OAK RIDGE
$\frac{\text { NATIONAL LABORATORY }}{\text { MANAGED BY UT-BATTELLE }}$
FOR THE DEPARTMENT OF ENERGY

\author{
Final Report \\ for \\ CRADA No. ORNL 98-499 \\ with \\ Agere Systems, Inc.
}

\title{
Critical Vacancy-Driven Phenomena in High-Energy \\ Ion-Implanted Silicon
}

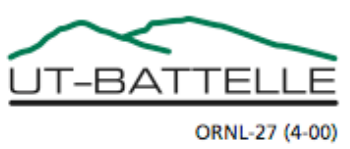


Reports produced after January 1, 1996, are generally available free via the U.S. Department of Energy (DOE) Information Bridge.

Web site http://www.osti.gov/bridge

Reports produced before January 1, 1996, may be purchased by members of the public from the following source.

National Technical Information Service

5285 Port Royal Road

Springfield, VA 22161

Telephone 703-605-6000 (1-800-553-6847)

TDD 703-487-4639

Fax 703-605-6900

E-mail info@ntis.fedworld.gov

Web site http://www.ntis.gov/support/ordernowabout.htm

Reports are available to DOE employees, DOE contractors, Energy Technology Data Exchange (ETDE) representatives, and International Nuclear Information System (INIS)

representatives from the following source.

Office of Scientific and Technical Information

P.O. Box 62

Oak Ridge, TN 37831

Telephone 865-576-8401

Fax 865-576-5728

E-mail reports@adonis.osti.gov

Web site http://www.osti.gov/contact.html

This report was prepared as an account of work sponsored by an agency of the United States Government. Neither the United States Government nor any agency thereof, nor any of their employees, makes any warranty, express or implied, or assumes any legal liability or responsibility for the accuracy, completeness, or usefulness of any information, apparatus, product, or process disclosed, or represents that its use would not infringe privately owned rights. Reference herein to any specific commercial product, process, or service by trade name, trademark, manufacturer, or otherwise, does not necessarily constitute or imply its endorsement, recommendation, or favoring by the United States Government or any agency thereof. The views and opinions of authors expressed herein do not necessarily state or reflect those of the United States Government or any agency thereof. 
Project Title: Critical Vacancy-Driven Phenomena in High-Energy Ion-Implanted Silicon

ID: ORNL 98-499

PI: Tony E. Haynes, Solid State Division, Oak Ridge National Laboratory

Phone: (865) 576-2858

Partners: Agere Systems Inc., Murray Hill, NJ

Final year funding, FY 2001: $\quad \$ 242 \mathrm{~K}$

Total Project Funds: \$732K

\section{Background}

High-energy $(\mathrm{MeV})$ ion implantation is now being rapidly introduced into integrated circuit manufacturing because it promises process simplification and improved device performance. However, high-energy implantation introduces an imbalance of excess vacancies and vacancy-cluster defects in the near-surface region of a silicon crystal. These defects interact with dopants affecting diffusion and electrical activation during subsequent processing.

\section{$\underline{\text { Research Objective }}$}

The objective of this project was to develop sufficient understanding of the physical mechanisms underlying the evolution of these defects and interactions with dopant atoms to enable accurate prediction and control of dopant diffusion and defect configurations during processing. This project supported the DOE mission in science and technology by extending ongoing Basic Energy Sciences programs in ion-solid physics and x-ray scattering at ORNL into new areas. It also strengthened the national capability for advanced processing of electronic materials, an enabling technology for DOE programs in energy conversion, use, and defense.

\section{$\underline{\text { Results }}$}

A systematic method to generate large, controllable, and spatially-isolated vacancy concentrations in silicon was developed using high-energy implantation. This method permitted unprecedented flexibility and sensitivity in experiments designed to measure interactions involving vacancies and vacancy-clusters. The evolution of vacancy profiles during thermal treatments was monitored using two new methods developed by the CRADA team. These methods were:

(a) measurement of vacancy cluster depth-profiles by labeling the clusters with gold atoms, and 
(b) measurement of x-ray diffuse scattering profiles in cross-section using a submicron x-ray beam at the Advanced Photon Source.

The list of CRADA accomplishments includes the following:

1. measurements of the number of excess vacancies produced per ion implanted as a function of ion mass and comparison of this number to simulation;

2. determination of the binding energy of vacancies to vacancy clusters in silicon;

3. enhanced electrical activation of certain dopants; and

4. observation of a new peak in the vacancy profile near the oxide-silicon interface following high-energy implantation into silicon-on-insulator substrates.

These findings were reported in journal publications and conference presentations. In addition, one patent filing resulted from finding $\mathrm{C}$ above. A complete list of publications follows below. Summary publications 1-4 listed below correspond respectively to each of the above accomplishments. Copies of these summary publications are included as attachments to this report.

\section{DOCUMENTATION OF CRADA ACCOMPLISHMENTS}

\section{Patents (copy of cover page attached)}

US Patent No. 6,632,728 - H.-J. L. Gossmann, T. E. Haynes, R. Kalyanaraman, L. Pelaz, C. S. Rafferty, and V. C. Venezia, "Increasing the electrical activation of ion-implanted dopants," assigned to CRADA Partner, Agere Systems Inc. (Allentown, PA); application filed July 16, 2001; patent issued October 14, 2003.

\section{Summary Publications in Refereed Journals (copies attached)}

1. R. Kalyanaraman, T. E. Haynes, V. C. Venezia, D. C. Jacobson, H.-J. Gossmann, and C. S. Rafferty, "Quantification of excess vacancy defects from high-energy ion implantation in Si by Au labeling," Appl. Phys. Lett. 76, 3379 (2000).

2. R. Kalyanaraman, T. E. Haynes, O. W. Holland, H.-J. Gossmann, C. S. Rafferty, and G. H. Gilmer, "Binding energy of vacancies to clusters formed in Si by high-energy ion implantation," Appl. Phys. Lett. 79,1983 (2001).

3. R. Kalyanaraman, V. C. Venezia, L. Pelaz, T. E. Haynes, H.-J. L. Gossmann, and C. S. Rafferty, "Enhanced low-temperature electrical activation of B in Si," Appl. Phys. Lett. 82, 215 (2003).

4. R. Kalyanaraman, T. E. Haynes, O. W. Holland, and G. H. Gilmer, "Character of defects at an ion-irradiated buried thin-film interface," J. Appl. Phys. 91, 6325 (2002). 


\section{$\underline{\text { Additional Publications (reprints available upon request) }}$}

\section{Refereed Journal Articles}

5. V. C. Venezia, D. J. Eaglesham, T. E. Haynes, A. Agarwal, D. C. Jacobson, H.-J. Gossmann, and F. H. Baumann, "Depth profiling of vacancy clusters in MeVimplanted Si using Au labeling," Appl. Phys. Lett. 73, 2980 (1998).

6. V. C. Venezia, T. E. Haynes, A. Agarwal, L. Pelaz, H.-J. Gossmann, D. C. Jacobson, and D. J. Eaglesham, "Mechanism for the reduction of interstitial supersaturations in medium-energy ion-implanted silicon following MeV co-implantation," App. Phys. Lett. 74, 1299 (1999).

7. M. Yoon, B. C. Larson, J. Z. Tischler, T. E. Haynes, J.-S. Chung, G. E. Ice, and P. Zschack, "Use of x-ray microbeams for cross-section depth profiling of $\mathrm{MeV}$ ionimplantation induced defect clusters in silicon," Appl. Phys. Lett. 75, 2791 (1999).

8. V. C. Venezia, R. A. Brown, R. Kalyanaraman, T. E. Haynes, O. W. Holland, and J. S. Williams, "Comment on 'Interstitial-type defects away from the projected ion range in high-energy ion implanted and annealed silicon,' by Kogler, et al.", Appl. Phys. Lett. 77, 151 (2000).

9. R. Kalyanaraman, T. E. Haynes, M. Yoon, B. C. Larson, D. C. Jacobson, H.-J. Gossmann, and C. S. Rafferty, "Quantitative evolution of vacancy-type defects in high-energy ion-implanted $\mathrm{Si}$ : Au labeling and the vacancy implanter," Nucl. Instrum. Meth. B 175-177, 182-186 (2001).

10. V. C. Venezia, L. Pelaz, H.-J. Gossmann, T. E. Haynes, and C. S. Rafferty, "The binding energy of vacancy clusters generated by high-energy ion implantation and annealing in silicon," Appl. Phys. Lett. 79, 1273 (2001).

11. V. C. Venezia, L. Pelaz, H.-J. L. Gossmann, A. Agarwal, and T. E. Haynes, "Radiation enhanced diffusion of $\mathrm{Sb}$ and $\mathrm{B}$ in silicon during implantation below $400^{\circ}$ C," Phys. Rev. B 69, 125215 (2004).

\section{Conference Proceedings Articles}

12. V.C. Venezia, D. J. Eaglesham, T. E. Haynes, Aditya Agarwal, D. C. Jacobson, H.-J. Gossmann, Thomas Friessnegg, and Bent Nielsen, "Vacancy supersaturations produced by high-energy ion implantation," p. 926 in Semiconductor Silicon 1998 (Electrochem. Soc. Proc. 98-1), edited by H. Huff, U. Gösele, and H. Tsuya (The Electrochemical Society, Pennington, NJ, 1998).

13. V. C. Venezia, T. E. Haynes, A. Agarwal, H.-J. Gossmann, L. Pelaz, D. C. Jacobson, D. J. Eaglesham, and J. L. Duggan,"Defects and diffusion in MeV-implanted silicon," p. 784 in Proc. 15th Int'l Conf. on Applic. of Accelerators in Research and Industry, edited by J. L. Duggan and I. V. Morgan (Am. Inst. Phys., New York, 1999). 
14. M. Yoon, B. C. Larson, J. Z. Tischler, T. E. Haynes, J.-S. Chung, G. E. Ice, and P. Zschack, "Use of x-ray microbeams for depth-profiling of $\mathrm{MeV}$ ion-implantation induced defect clusters in silicon," pp. 175-186 in Proceedings of 1999 Advanced Study Institute on Exploration of subsurface phenomena by particle scattering held Oct. 19-23, 1998, Monterey, CA; ed. by N. Q. Lam, C. A. Melendres, \& S. K. Sinha (Am. Inst. Phys., New York).

15. R. Kalyanaraman, T. E. Haynes, V. C. Venezia, D. C. Jacobson, H.-J. Gossmann, and C. S. Rafferty, "Calibration of the Au labeling technique to measure vacancy defects in silicon," p. B9.2.1 in Si Front-End Processing- Physics and Technology of DopantDefect Interactions II, edited by A. Agarwal, L. Pelaz, H.-H. Vuong, P. Packan, and M. Kase, Materials Research Society, Pittsburgh, PA (2000). [MRS Symp. Proc. 610, B9.2.1 (2000).]

16. R. Kalyanaraman, T. E. Haynes, D. C. Jacobson, H.-J. Gossmann, and C. S. Rafferty "Quantitative Profiles of Vacancy Cluster Defects Produced by $\mathrm{MeV}$ Ion Implantation in Si: Species and Dose Dependence," p. B9.4.1 in Si Front-End Processing- Physics and Technology of Dopant-Defect Interactions II, edited by A. Agarwal, L. Pelaz, H.-H. Vuong, P. Packan, and M. Kase, Materials Research Society, Pittsburgh, PA (2000). [MRS Symp. Proc. 610, B9.4.1 (2000).] 
Attachments

Date of Report: 11/11/2008 
(This page intentionally left blank.) 


\section{(12) United States Patent Gossmann et al.}

(10) Patent No.

US 6,632,728 B2

(45) Date of Patent:

Oct. 14, 2003

(54) INCREASING THE ELECTRICAL ACTIVATION OF ION-IMPLANTED DOPANTS

(75) Inventors: Hans-Joachim Ludwig Gossmann, Summit, NJ (US); Conor Stefan Rafferty, New York City, NY (US); Tony E. Haynes, Knoxville, TN (US); Ramki Kalyanaraman, University City, MO (US); Vincent C. Venezia, Leuven (BE); Maria Lourdes Pelaz-Montes, Valladolid (ES)

(73) Assignee: Agere Systems Inc., Allentown, PA (US)

(*) Notice: Subject to any disclaimer, the term of this patent is extended or adjusted under 35 U.S.C. 154(b) by 0 days.

(21) Appl. No.: 09/906,211

(22) Filed: Jul. 16, 2001

Prior Publication Data

US 2003/0013260 A1 Jan. 16, 2003

(51) Int. $\mathrm{Cl}^{7}$ H01L 21/265

(52) U.S. Cl. 438/527; $538 / 528 ; 538 / 530$

(58) Field of Search $438 / 510,514$ $438 / 517,527,528,530$

\section{References Cited}

\section{U.S. PATENT DOCUMENTS}

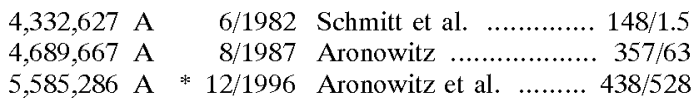

(List continued on next page.)

\section{FOREIGN PATENT DOCUMENTS}

\section{OTHER PUBLICATIONS}

Venezia et al., Mechanism for the reduction ..., Appl. Phys. Lett., vol. 74, No. 9, pp. 1299-1301 (Mar. 1999).

Jin et al., Vacancy Enhanced Boron . . , MRS Symp. Proc., Paper B5.6, pp. 1-6, San Francisco, CA. Talk given on Apr. $26,2000$.

Larsen et al., The damage recovery and electrical activation ... , Nuclear Instruments and Methods in Physics Research B, vol. 112, pp. 139-143 (1996).

Saito, Defect reduction by MeVion implantation ... , Appl. Phys. Lett., vol. 63, No. 2, pp. 197-199 (Jul. 1993).

Pelaz et al., B diffusion and clustering . . , Appl. Phys. Lett., vol. 70, No. 17, pp. 2285-2287 (Apr. 1997).

Primary Examiner-Savitri Mulpuri

(74) Attorney, Agent, or Firm-Michael J. Urbano

\section{ABSTRACT}

We have found that under certain prescribed conditions a co-implantation process can be effective in increasing the electrical activation of implanted dopant ions. In accordance with one aspect of our invention, a method of making a semiconductor device includes the steps of providing a single crystal semiconductor body, implanting vacancygenerating, ions into a preselected region of the body, implanting dopant ions into the preselected region, the dopant implant forming interstitial defects in the body, and annealing the body to electrically activate the dopant ions. Importantly, in our method the vacancy-generating implant introduces vacancy defects into the preselected region that are effective to annihilate the interstitial defects. In addition, process steps that amorphize the surface of the implanted region are avoided, and the dose of the vacancy-generating implant is made to be greater than that of the dopant implant. In a preferred embodiment, the peak of the vacancy defect concentration profile substantially overlaps the peak of the dopant implant concentration profile. In another preferred embodiment the peak of the vacancy-generating implant profile is deeper than that of the dopant profile. In accordance with another aspect of our invention, after ion implantation is complete, only low temperature process steps (e.g., steps performed at temperatures no greater than about $800^{\circ}$ C. for Si devices) are performed.

10 Claims, 2 Drawing Sheets

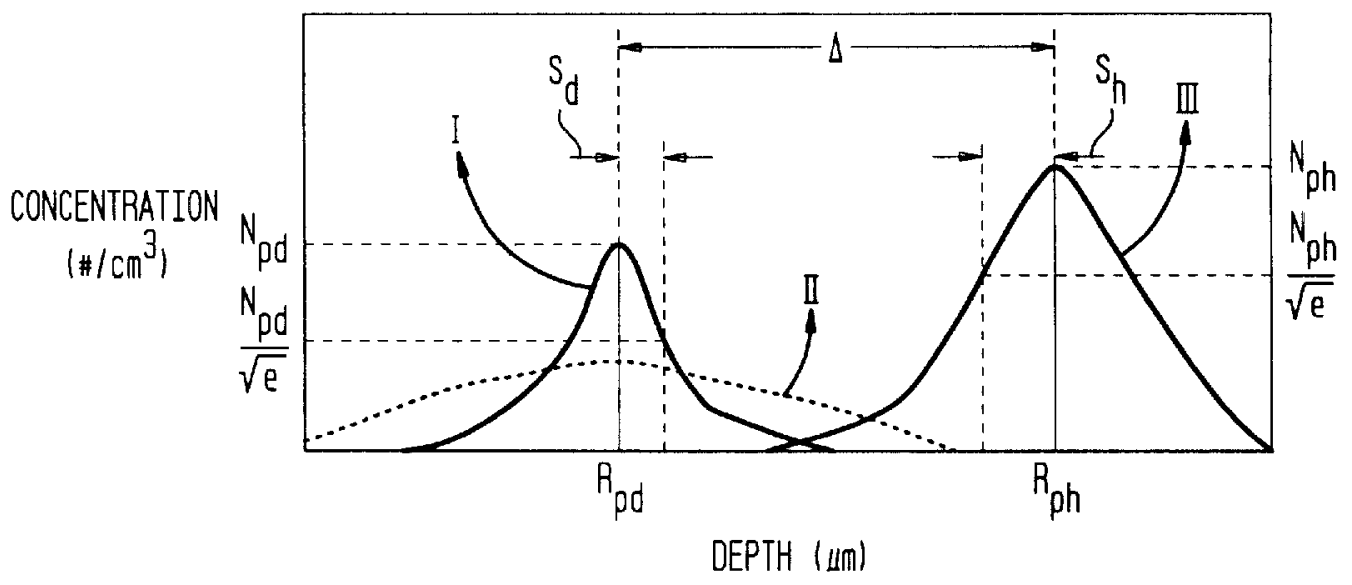


(This page intentionally left blank.) 


\title{
Quantification of excess vacancy defects from high-energy ion implantation in Si by Au labeling
}

\author{
R. Kalyanaraman ${ }^{\mathrm{a})}$ and T. E. Haynes \\ Solid State Division, Oak Ridge National Laboratory, Oak Ridge, Tennessee 37831 \\ V. C. Venezia, D. C. Jacobson, H.-J. Gossmann, and C. S. Rafferty \\ Bell Laboratories, Lucent Technologies, Murray Hill, New Jersey 07974
}

(Received 13 March 2000; accepted for publication 12 April 2000)

\begin{abstract}
It has been shown recently that Au labeling [V. C. Venezia, D. J. Eaglesham, T. E. Haynes, A. Agarwal, D. C. Jacobson, H.-J. Gossmann, and F. H. Baumann, Appl. Phys. Lett. 73, 2980 (1998)] can be used to profile vacancy-type defects located near half the projected range $\left(\frac{1}{2} R_{p}\right)$ in $\mathrm{MeV}$-implanted Si. In this letter, we have determined the ratio of vacancies annihilated to Au atoms trapped (calibration factor ' " $k$ ") for the Au-labeling technique. The calibration experiment consisted of three steps: (1) a $2 \mathrm{MeV} \mathrm{Si}^{+}$implant into $\mathrm{Si}(100)$ followed by annealing at $815^{\circ} \mathrm{C}$ to form stable excess vacancy defects; (2) controlled injection of interstitials in the $\frac{1}{2} R_{p}$ region of the above implant via $600 \mathrm{keV} \mathrm{Si}^{+}$ions followed by annealing to dissolve the $\{311\}$ defects; and (3) $\mathrm{Au}$ labeling. The reduction in Au concentration in the near-surface region $(0.1-1.6 \mu \mathrm{m})$ with increasing interstitial injection provides the most direct evidence so far that $\mathrm{Au}$ labeling detects the vacancy-type defects. By correlating this reduction in Au with the known number of interstitials injected, it was determined that $k=1.2 \pm 0.2$ vacancies per trapped $\mathrm{Au}$ atom. (C) 2000 American Institute of Physics. [S0003-6951(00)00723-3]
\end{abstract}

Renewed interest in the use of high-energy ion implantation (HEI) in $\mathrm{Si}$ as a cost-effective device processing step ${ }^{1,2}$ has created a serious need to understand defects resulting from such implants. In particular, the higher average forward momentum of recoiled atoms produced in the collision cascades results in an excess of vacancy-type defects in the shallow part of the implant profile. ${ }^{3}$ While interstitial-type defects at the projected range $\left(R_{p}\right)$ of the implants in Si have been well studied, ${ }^{4}$ much less is known about defects in the near-surface region of these implants. The reason for this is primarily due to the inability of current techniques to reliably detect or quantify vacancy-type defects. In this work, we show that it is possible to not only detect but also quantify vacancy-type defects in Si using the Au-labeling technique previously described by Venezia and co-workers. ${ }^{5}$ Controlled vacancy removal and counting was achieved in a three-step experiment. First, stable vacancy-type defects were formed by a $2 \mathrm{MeV} \mathrm{Si}^{+}$implant and anneal. ${ }^{5}$ Second, controlled vacancy removal was achieved by medium-energy $(600 \mathrm{keV}) \mathrm{Si}^{+}$implants of various doses followed by a second anneal $(+\mathrm{I}$ implant and anneal). The third and final step was to measure the change in vacancy concentration by saturating the $\mathrm{Au}$ in the $\frac{1}{2} R_{p}$ region by Au labeling. The vacancy removal results in less Au being trapped afterward. Correlation of the concentration of trapped Au with the number of vacancies removed provides a measurement of the calibration factor $k$, which is the ratio of vacancies annihilated to $\mathrm{Au}$ atoms trapped in the Au-labeled profiles. This determination of $k$ allows unambiguous, quantitative measurement of the vacancy concentrations produced by high-energy implantation in Si.

${ }^{a)}$ Electronic mail: ramkik@lucent.com
In 1996, Holland and co-workers ${ }^{6}$ showed from transmission electron microscopy (TEM) studies that extended vacancy-type defects form in the near-surface region for extremely high-dose implants. Other groups extended this finding of vacancy-type defects to more moderate implantation doses via $x$-ray diffraction strain measurements ${ }^{7}$ and positron annihilation spectroscopy (PAS) $S$-parameter measurements. ${ }^{8}$ These findings suggest that precursors to the large open-volume defects of the Holland et al. work ${ }^{6}$ are the free vacancies resulting from the displacement of interstitials with respect to vacancies occurring in heavy-ion and/or highenergy implants. Presently, techniques like PAS, x-ray strain measurements, and TEM are capable of detecting vacancytype defects, but cannot accurately quantify the concentration of vacancies present. While TEM is capable of quantitative measurements of open-volume defects of large sizes, small vacancy clusters are difficult to detect. More recently, cross-section x-ray diffuse scattering ${ }^{9}$ has been used to make a quantitative estimate of excess vacancy-type defects from a $10 \mathrm{MeV}$ Si self-implant. While it is, in principle, possible to deconvolute the defect size and concentration by diffuse scattering, this has not yet been accomplished for HEI in the energy range of interest. Recently, Venezia et al. ${ }^{5}$ used gettering of $\mathrm{Au}$ atoms to obtain depth profiles of the defects in the $\frac{1}{2} R_{p}$ region of $\mathrm{MeV}$ self-implants in $\mathrm{Si}$. The motivation for using Au was based on two principal factors: (a) the kick-out mechanism ${ }^{10}$ that controls diffusion of Au in Si implies that Au will be trapped in the vicinity of interstitial sinks, including vacancy-type defects, and (b) the good sensitivity of Rutherford backscattering (RBS) to detect Au in $\mathrm{Si}$. In this work, we establish the quantitative capability of this technique to profile the concentration of vacancies in the near-surface region formed by a $2 \mathrm{MeV}$ self-implant in $\mathrm{Si}$. 

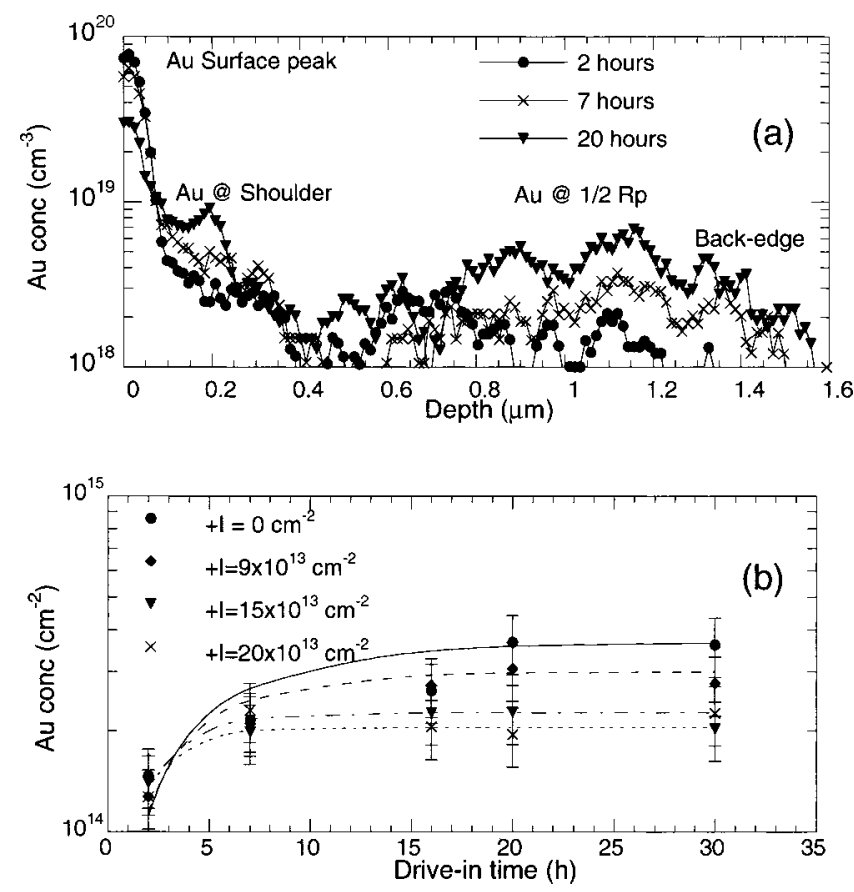

FIG. 1. (a) RBS profiles of Au concentration in the HEl sample for various Au drive-in times. (b) Au concentration at $\frac{1}{2} R_{p}(0.5-1.6 \mu \mathrm{m})$ vs drive-in time. Smooth curves are fits of type $C_{0}\left(1-\exp ^{-t / \tau}\right)$. Error bars are $\pm 20 \%$.

$P$-type float-zone $\operatorname{Si}(100)(\rho=65-80 \Omega \mathrm{cm})$ wafers were first implanted with $2 \mathrm{MeV} \mathrm{Si}\left(R_{p} \sim 2 \mu \mathrm{m}\right)$ with a dose of 1 $\times 10^{16} \mathrm{~cm}^{-2}$ at an angle of $7^{\circ}$ from the surface-normal direction using a $1.7 \mathrm{MeV}$ National Electrostatics tandem Pelletron. The substrate temperature during the implant was maintained at $70-80^{\circ} \mathrm{C}$, while the chamber pressure was between 2 and $5 \times 10^{-6}$ Torr. The implanted samples were then furnace annealed at $815^{\circ} \mathrm{C}$ for $20 \mathrm{~min}$ (henceforth, referred to as the HEI sample) in 1 atm of argon. After this anneal, interstitial injection was carried out by implanting $600 \mathrm{keV}$ $\mathrm{Si}^{+}$ions at doses from $5 \times 10^{13}$ to $20 \times 10^{13} \mathrm{~cm}^{-2}$ followed by an $765^{\circ} \mathrm{C}, 20 \mathrm{~min}$ anneal in flowing Ar. The projected range of this implant is $\sim 0.9 \mu \mathrm{m}$ [from SRIM-2000 (Ref. 11)], which puts it almost at $\frac{1}{2} R_{p}$ of the $2 \mathrm{MeV} \mathrm{Si}^{+}$implant. The dose range for the $+\mathrm{I}$ implant was chosen to stay below the threshold dose for forming dislocation loops in order to ensure that any clusters or extended defects containing interstitials would be completely dissolved in the $765^{\circ} \mathrm{C}$ anneal. Finally, the Au labeling was carried out by implanting Au at $68 \mathrm{keV}\left(R_{p} \sim 0.03 \mu \mathrm{m}\right)$ and $8 \times 10^{14} \mathrm{~cm}^{-2}$ dose in the HEI samples and the HEI $+I$ samples. The implanted Au was diffused in at $750{ }^{\circ} \mathrm{C}$ in $1 \mathrm{~atm}$ of argon for times up to $30 \mathrm{~h}$. The Au concentration profiles were then measured by RBS in random geometry, using $2.8 \mathrm{MeV}{ }^{4} \mathrm{He}^{2+}$ at an incident angle of $22^{\circ}$ relative to the surface-normal direction with the detector at $170^{\circ}$ from the incident ion direction.

Figure 1(a) shows typical RBS profiles of $\mathrm{Au}$ in the near-surface region of the HEI samples for different $\mathrm{Au}$ indiffusion times. Besides the Au-implant peak at the surface, a broad peak appears in the $\frac{1}{2} R_{p}$ region around $\sim 0.5-1.6$ $\mu \mathrm{m}$ as well as a narrower "shoulder" 12 peak near $0.2 \mu$. As the data show, there is a substantial increase in Au at both the shoulder and $\frac{1}{2} R_{p}$ in going from 2 to $20 \mathrm{~h}$ of Au drive-in time, indicating that the Au concentration takes considerable time to saturate for a HEI dose of $1 \times 10^{16} \mathrm{~cm}^{-2}$. With re-
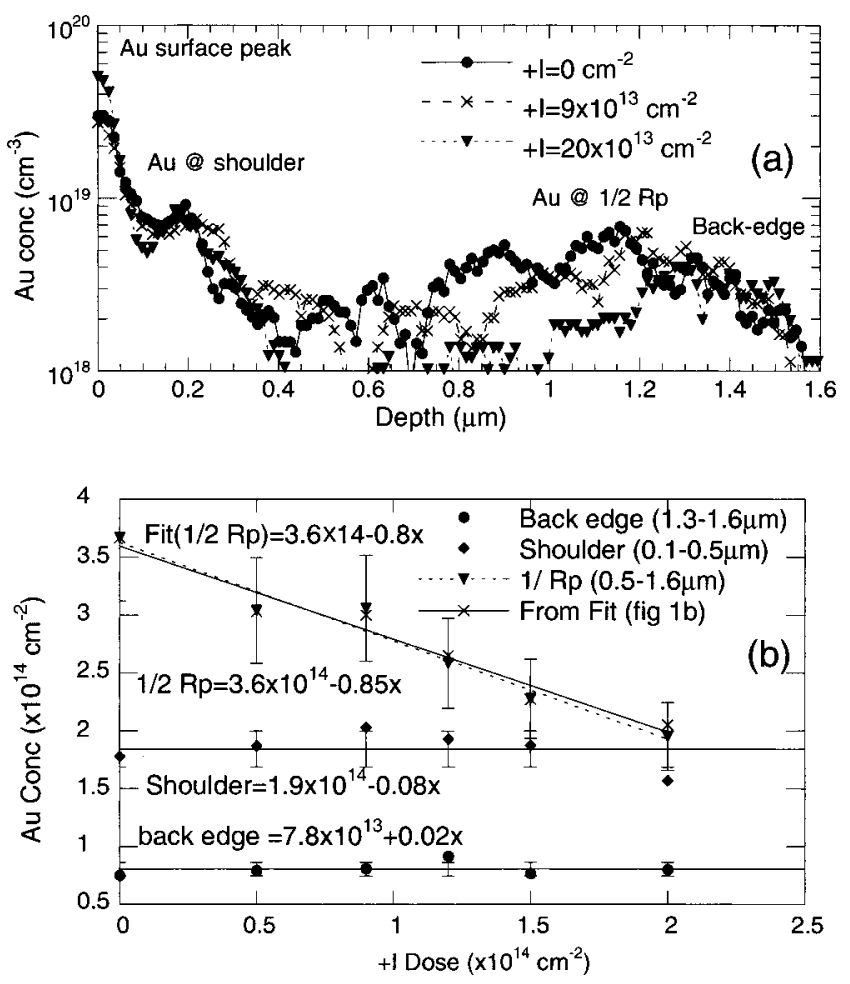

FIG. 2. (a) RBS profiles of Au concentration after $20 \mathrm{~h}$ drive-in for various +1 doses. (b) Au concentration vs $+\mathrm{I}$ dose. Error bars on back-edge and shoulder data are $\pm 1 \sigma$ and those on $\frac{1}{2} R_{p}$ are $\pm 10 \%$.

spect to the earlier qualitative work by Venezia et al., ${ }^{5}$ accurate quantification of this technique required that the $\mathrm{Au}$ and vacancy-type defect interaction be taken to completion. The saturation characteristics of the Au profiles in the $\frac{1}{2} R_{p}$ region $(0.5-1.6 \mu \mathrm{m})$ for the HEI sample and with various $+\mathrm{I}$ doses are plotted as a function of time in Fig. 1(b). The smooth curves in Fig. 1(b) are exponential fits of the type $C$ $=C_{0}\left(1-e^{-\mathrm{t} / \tau}\right)$, where $C_{0}$ and $\tau$ are the saturated Au concentration and saturation time constant, respectively. Based on the experimental data and fits, a standard drive-in time of $20 \mathrm{~h}$ at $750{ }^{\circ} \mathrm{C}$ was considered sufficient to saturate all the samples.

Figure 2(a) compares RBS results after $20 \mathrm{~h} \mathrm{Au}$ drive-in for the HEI and HEI $+\mathrm{I}\left(+\mathrm{I}=9 \times 10^{13}\right.$ and $\left.20 \times 10^{13} \mathrm{~cm}^{-2}\right)$ samples. The most important features in Fig. 2(a) are: (a) the reduction of the amount of trapped Au in the region between 0.5 and $1.3 \mu \mathrm{m}$, indicating that interstitials do react with the vacancies; (b) the Au concentration in the shoulder is almost constant as a function of the $+\mathrm{I}$ dose; and (c) the back edge of the profiles at $\sim 1.3-1.6 \mu \mathrm{m}$ match up for all the doses. Features (b) and (c) indicate that there is no interstitialvacancy reaction taking place either shallower than $0.5 \mu \mathrm{m}$ or deeper than $1.3 \mu \mathrm{m}$, demonstrating that the $+\mathrm{I}$ interstitials do not escape from the $0.5-1.3 \mu \mathrm{m}$ region of the excess vacancy profile. These features are seen quantitatively in Fig. 2(b), which plots the dependence of the integrated Au concentrations on $+\mathrm{I}$ for the shoulder, $\frac{1}{2} R_{p}$, and back edge after $20 \mathrm{~h}$ of Au drive-in. The relatively small change in the shoulder and back edge over the whole $+\mathrm{I}$ dose range studied indicates that the interstitial+vacancy interaction is confined to the $\frac{1}{2} R_{p}$ region.

To obtain $k$, the slope of the change in Au concentration 
at $\frac{1}{2} R_{p}$ with respect to the injected $+\mathrm{I}$ interstitial dose was obtained from Fig. 2(b). The slope for the $\frac{1}{2} R_{p} \mathrm{Au}$ is 0.85 $\pm 15 \%$ for the $20 \mathrm{~h}$ Au drive-in samples, while the slope obtained by using the saturated Au concentrations from the fits of the time dependence [Fig. 1(b)] is 0.80 . The close agreement between the two numbers confirms that $20 \mathrm{~h}$ does give the saturated value. More importantly, the slope indicates that approximately $1.2 \pm 0.2$ interstitials are required to decrease the Au concentration by 1 atom. Under the assumptions that 1 interstitial consumes 1 vacancy and that Au reacts with all the vacancy-type defects, ${ }^{13}$ this indicates that $k$ is approximately $1.2 \pm 0.2$ vacancies for every trapped $\mathrm{Au}$ atom.

The validity of the obtained factor was supported by additional experiments, as follows. (a) Cross-section TEM comparison of $+\mathrm{I}$ implants in the HEI sample and in bare wafers typically showed that, while no defects appeared in the HEI sample, $\{311\}$-type defects were observed for the + I dose, indicating that vacancies from the HEI suppress extended interstitial-type defect formation; (b) the $\frac{1}{2} R_{p}$ of the $600 \mathrm{keV}$ implants in bare Si wafers did not getter $\mathrm{Au}$; and (c) loop detectors ${ }^{14}$ placed at the surface confirmed that no fraction of the $+\mathrm{I}$ implant was lost to the surface.

From Fig. 1(a), the concentration of $\mathrm{Au}$ at $\frac{1}{2} R_{p}(\sim 3$ $\left.\times 10^{18} \mathrm{~cm}^{-3}\right)$ is seen to greatly exceed the solubility of $\mathrm{Au}$ at $750^{\circ} \mathrm{C}\left(\sim 2 \times 10^{14} \mathrm{~cm}^{-3}\right) \cdot{ }^{15}$ Cross-section TEM was carried out on the HEI sample after $20 \mathrm{~h}$ of drive-in to determine the state of Au. The sample showed a distribution of precipitates of 3-15 $\mathrm{nm}$ in size consisting of fcc Au (determined by selected area diffraction). Additionally, no extended interstitial defects, usually observed in the case of Au-silicide precipitation ${ }^{16}$ were observed. While these results suggest that metallic Au precipitates form as a result of interaction with the vacancies, the exact mechanism is still unclear. Additional features of the Au profile in Fig. 1(a), are the dips in $\mathrm{Au}$ concentration between 0.3 and $0.5 \mu \mathrm{m}$, and the appearance of $\mathrm{Au}$ in the shoulder. In a simplistic approach, the dip may be explained by loss of vacancies to the surface during the anneal step after the HEI. Preliminary results on the appearance of the shoulder suggest that it may be related to knock-on implantation of surface impurities during the HEI. ${ }^{12}$

The fact that $k$ is so close to 1 indicates that Au capture is more likely a space filling of the $\mathrm{MeV}$-implant related vacancy clusters. This is in contrast to the observations of Follstaedt et al. ${ }^{17}$ who found that the Au concentration saturates when $1 \mathrm{ML}$ of $\mathrm{Au}$ coats the walls of He-induced voids in $\mathrm{Si}$. However, significant differences between the present experiments and those of Follstaedt, chiefly the sizes of the voids and the drive-in conditions, may account for the different observations. Currently, work is underway to deter- mine the capture mechanism for $\mathrm{Au}$ by $\mathrm{MeV}$-implant related vacancy clusters, especially to distinguish between mechanisms of kick-in and direct capture of Au at vacancy clusters. Nevertheless, independent of the mechanism, the $A u$ labeling technique provides a simple and effective tool to detect and count excess vacancies. The detection of vacancies by this technique will be limited only by the ability to detect $\mathrm{Au}$ in $\mathrm{Si}$, while the lowest measurable vacancy concentration will be set by the solubility of $\mathrm{Au}$ in $\mathrm{Si}$ at the drive-in temperature. Subject to this, there appears no apparent impediment to extending this technique to measure vacancies produced in Si by other means.

One of the authors (R.K.) would like to thank G. Gilmer, J. Benton, and F. Baumann for stimulating discussions and help with TEM. This research was supported in part by the U.S. Department of Energy, Office of Science, Laboratory Technology Division under Contract No. DE-AC0596OR22464 with Lockheed Martin Energy Research Corp. and Contract No. DE-AC05-76OR00033 with Oak Ridge Associated Universities.

${ }^{1}$ K. Tsukamoto, S. Komori, T. Kuroi, and Y. Akasaka, Nucl. Instrum. Methods Phys. Res. B 59/60, 572 (1991).

${ }^{2}$ L. Rubin and W. Morris, Semicond. Int. 20, 77 (1997).

${ }^{3}$ A. M. Mazzone, Phys. Status Solidi A 95, 149 (1986).

${ }^{4}$ J. Y. Cheng, D. J. Eaglesham, D. C. Jacobson, P. A. Stolk, J. L. Benton, and J. M. Poate, J. Appl. Phys. 80, 2105 (1996).

${ }^{5}$ V. C. Venezia, D. J. Eaglesham, T. E. Haynes, A. Agarwal, D. C. Jacobson, H.-J. Gossmann, and F. H. Baumann, Appl. Phys. Lett. 73, 2980 (1998).

${ }^{6}$ O. W. Holland, L. Xie, B. Nielsen, and D. S. Zhou, J. Electron. Mater. 25, 99 (1996).

${ }^{7}$ S. L. Ellingboe and M. C. Ridgway, Nucl. Instrum. Methods Phys. Res. B 127/128, 90 (1997).

${ }^{8}$ C. Szeles, B. Nielsen, P. Asoka-Kumar, K. G. Lynn, M. Anderle, T. P. Ma, and G. W. Rubloff, J. Appl. Phys. 76, 3403 (1994).

${ }^{9}$ M. Yoon, B. C. Larson, J. Z. Tischler, T. E. Haynes, J.-S. Chung, G. E. Ice, and P. Zschack, Appl. Phys. Lett. 75, 2791 (1999).

${ }^{10}$ U. Gösele, W. Frank, and A. Seeger, Appl. Phys. 23, 361 (1980).

${ }^{11}$ J. F. Ziegler, J. P. Bierszack, and U. Littmark, The Stopping and Ranges of Ions in Solids (Pergamon, New York, 1985).

${ }^{12} \mathrm{We}$ have evidence that the shoulder is also due to vacancies. For example, the Au concentration in the shoulder decreases when the energy of the $+\mathrm{I}$ implant is reduced to $350 \mathrm{keV}$ so that some of the interstitials can escape annihilation at the $\frac{1}{2} R_{p}$. This shoulder was not seen in samples without a HEl. Quantitative findings regarding this shoulder peak will be reported in a more detailed paper to be submitted later.

${ }^{13}$ Preliminary results from positron annihilation experiments (PAS) show that the vacancy-type signal ( $S$ parameter) for a HEl sample with increasing $\mathrm{Au}$ drive-in time decreases as Au concentration at $\frac{1}{2} R_{p}$ increases.

${ }^{14}$ J. K. Listebarger, K. S. Jones, and J. A. Slinkman, J. Appl. Phys. 73, 4815 (1993).

${ }^{15} \mathrm{~K}$. Graff, Metal Impurities in Si-device Fabrication (Springer, New York, 1995).

${ }^{16}$ F. H. Baumann and W. Schroter, Phys. Rev. B 43, 6510 (1991).

${ }^{17}$ D. M. Follstaedt, S. M. Myers, G. A. Petersen, and J. W. Medernach, J. Electron. Mater. 25, 151 (1996). 
(This page intentionally left blank.) 


\title{
Binding energy of vacancies to clusters formed in Si by high-energy ion implantation
}

\author{
R. Kalyanaraman ${ }^{a)}$ \\ Solid State Division, Oak Ridge National Laboratory, Oak Ridge, Tennessee 37831 and \\ Agere Systems, Murray Hill, New Jersey 07974 \\ T. E. Haynes and O. W. Holland \\ Solid State Division, Oak Ridge National Laboratory, Oak Ridge, Tennessee 37831
}

H.-J. L. Gossmann, C. S. Rafferty, and G. H. Gilmer

Agere Systems, Murray Hill, New Jersey 07974

(Received 8 May 2001; accepted for publication 23 July 2001)

\begin{abstract}
Measurements of the binding energy $\left(E_{b}\right)$ of vacancies to vacancy clusters formed in silicon following high-energy ion implantation are reported. Vacancy clusters were created by $2 \mathrm{MeV}, 2$ $\times 10^{15} \mathrm{~cm}^{-2}$ dose Si implant and annealing. To prevent recombination of the excess vacancies $\left(V^{\mathrm{ex}}\right)$ with interstitials from the implant damage near the projected range $\left(R_{p}\right)$, a Si-on-insulator substrate was used such that the $R_{p}$ damage was separated from the $V^{\text {ex }}$ by the buried oxide (BOX). Two $V^{\text {ex }}$ regions were observed: one in the middle of the top Si layer $\left(V_{1}^{\mathrm{ex}}\right)$ and the other at the front $\mathrm{Si} / \mathrm{BOX}$ interface $\left(V_{2}^{\mathrm{ex}}\right)$. The rates of vacancy evaporation were directly measured by Au labeling following thermal treatments at temperatures between 800 and $900{ }^{\circ} \mathrm{C}$ for times ranging from 600 to $1800 \mathrm{~s}$. The rate of vacancy evaporation from $V_{2}^{\mathrm{ex}}$ was observed to be greater than from $V_{1}^{\mathrm{ex}}$. The binding energy of vacancies to clusters in the middle of the silicon top layer was $3.2 \pm 0.2 \mathrm{eV}$ as determined from the kinetics for vacancy evaporation. (C) 2001 American Institute of Physics.

[DOI: $10.1063 / 1.1405814]$
\end{abstract}

Techniques have recently been developed to generate large vacancy supersaturations ${ }^{1}$ in silicon by high-energy implantation $^{2}$ (HEI), to isolate these vacancies from the associated excess interstitials ${ }^{3}$ and to quantitatively profile the residual excess vacancies by Au labeling. ${ }^{4}$ Detailed studies of excess vacancy production and its dependence on ion mass, ${ }^{5}$ anneal temperature,${ }^{6}$ etc., have been carried out using these techniques. However, a number of basic questions regarding the behavior of the resulting vacancy clusters, such as their interactions with impurities, buried interfaces, and their thermodynamic properties, have yet to be addressed in detail. In this work, we present an experimental measurement of the binding energy $\left(E_{b}\right)$ of vacancies to vacancy clusters formed following high-energy implantation in silicon.

In earlier attempts to measure the evaporation rate of implantation-induced vacancy clusters in bulk $\mathrm{Si}$, it was found $^{3}$ that the rate is determined by recombination with interstitials from the $R_{p}$ damage, thus masking the intrinsic properties of the vacancy clusters. To prevent this interaction, it was proposed that a silicon-on-insulator (SOI) substrate $^{3}$ be used such that the buried oxide (BOX) layer would provide a barrier to interstitial migration, ${ }^{7}$ thus isolating the interstitials of the damage near $R_{p}$ from the $V^{\mathrm{ex}}$ region. Subsequently, a comparison of the thermal behavior of the $V^{\text {ex }}$ in various substrates showed ${ }^{8}$ that the $V^{\text {ex }}$ is more persistent in the SOI as compared to the bulk Si at any given temperature, thus validating this suggestion. In the present work, the cluster evaporation rate is measured in the SOI in

${ }^{a)}$ Electronic mail: ramkik@wuphys.wustl.edu order to eliminate the interstitial interactions and determine the $E_{b}$ of vacancies to clusters. Also, in the course of this study a phenomenon was found to accompany the implantation through the BOX layer. Such implantation results in an additional vacancy-rich region, $V_{2}^{\text {ex }}$, on the $\mathrm{Si}$ side of the front $\mathrm{Si} / \mathrm{BOX}$ interface. The thermal behavior of this additional vacancy peak was also studied and compared with the $V_{1}^{\mathrm{ex}}$ region.

The SOI wafer used in this work had an approximately 1.8- $\mu \mathrm{m}$-thick top Si layer, while the BOX layer was $0.2 \mu \mathrm{m}$ thick. The thick Si top layer was prepared by rapid thermal chemical-vapor deposition (RTCVD) of a $\sim 1.6-\mu$ m-thick Si layer on commercially available bonded SOI having a 0.2 $\mu \mathrm{m}$ silicon $p / p^{+}$epi-Si top layer. The substrate below the BOX was Czochralski silicon. The final $1.8 \pm 0.2-\mu \mathrm{m}$-thick $\mathrm{Si}$ was nominally undoped and the background $\mathrm{O}$ and $\mathrm{C}$ concentrations were below the SIMS detection limits of $\sim 5 \times 10^{17}$ and $\sim 5 \times 10^{16} \mathrm{~cm}^{-3}$, respectively. Crosssectional transmission electron microscopy analysis of the as-grown wafer did not reveal any bulk or interfacial defects. The $V^{\text {ex }}$ profile was created by implanting $2 \times 10^{15} \mathrm{~cm}^{-2}$ of $2 \mathrm{MeV}^{28} \mathrm{Si}^{+}$from a National Electrostatics Pelletron accelerator at an angle of $7^{\circ}$ to the substrate normal. The current density was $0.09 \mu \mathrm{Acm}^{-2}$ while the substrate temperature was held at $70^{\circ} \mathrm{C}$ to prevent amorphization. Since the $R_{p}$ of the $2 \mathrm{MeV}$ Si implant is $\sim 2 \mu \mathrm{m}$ with a straggle of $\sim 0.25 \mu \mathrm{m}$ [as calculated by TRIM 98 (Ref. 9)], the interstitial damage is behind the BOX layer. Following the HEI step the sample was RCA cleaned and annealed in a tube furnace at $800^{\circ} \mathrm{C}$ for $600 \mathrm{~s}$ under $1 \mathrm{~atm}$ of Ar (flow rate of $1.5 \mathrm{lpm}$ ). This preanneal served as the vacancy cluster-formation anneal and 


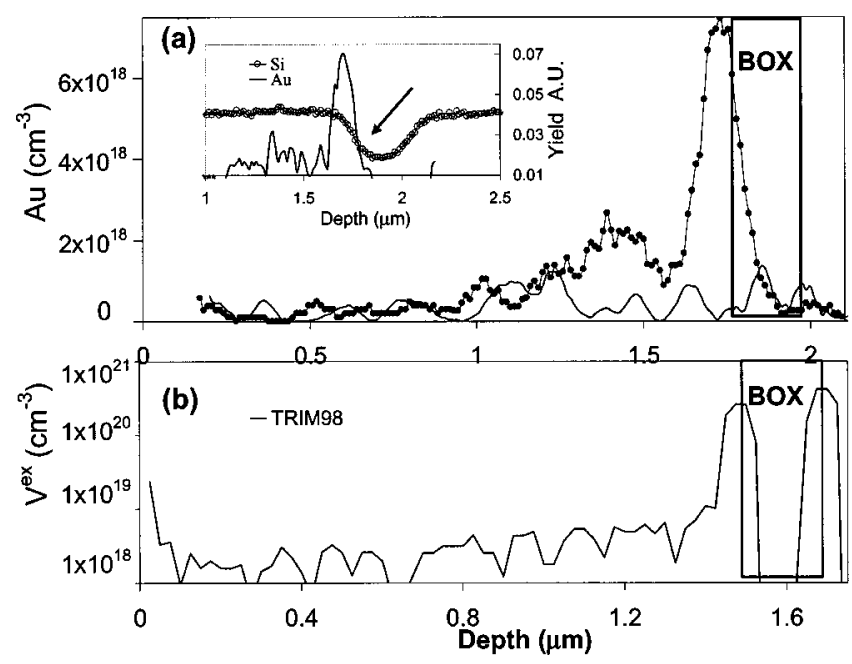

FIG. 1. (a) Au concentration after $2 \mathrm{MeV}, 2 \times 10^{15} \mathrm{~cm}^{-2} \mathrm{Si}$ implantation into SOI with preanneal (solid circles) and bulk FZ Si (solid line). The inset shows the position of the BOX interface (arrow) obtained by comparing the $\mathrm{Si}$ and $\mathrm{Au}$ signals. The BOX position with respect to the Au signal is indicated by the solid box. (b) TRIM simulation of a $2 \mathrm{MeV}, 2 \times 10^{15} \mathrm{~cm}^{-2} \mathrm{Si}$ implant into the SOI with a $1.5 \mu \mathrm{m}$ Si top layer on $0.2-\mu \mathrm{m}$-thick BOX showing the large $\left(V^{\mathrm{ex}}\right)$ at the front $\mathrm{Si} / \mathrm{BOX}$ interface.

the subsequent time and temperature behavior was measured after this anneal.

Following the preanneal, smaller pieces were cleaved and individually annealed under Ar flow as above at temperatures of 800,850 , and $900{ }^{\circ} \mathrm{C}$ for times from 600 to 1800 s. Finally, the vacancy profiles were measured using $\mathrm{Au}$ labeling ${ }^{4}$ by implanting $68 \mathrm{keV}{ }^{196} \mathrm{Au}^{+}$to a dose of 8 $\times 10^{14} \mathrm{~cm}^{-2}$, followed by a drive-in anneal at $750{ }^{\circ} \mathrm{C}$ (in 1 atm Ar with a flow rate of $1.5 \mathrm{lpm}$ ) for $9 \mathrm{~h}$. This anneal time was sufficient to saturate the $\mathrm{Au}$ in the $V^{\mathrm{ex}}$ regions. ${ }^{4}$ Rutherford backscattering (RBS) using $2.8 \mathrm{MeV}{ }^{4} \mathrm{He}^{2+}$ was performed to measure the resulting Au profiles. Calibration experiments reported previously have shown that under these conditions the $V^{\text {ex }}$ concentration is equal to the Au concentration multiplied by the calibration factor $k=1.2$. $^{4}$ Figure 1(a) shows the $\mathrm{Au}$ profile obtained after the HEI (with the preanneal) in the SOI substrate. Also shown is the profile for a similar implant (without the preanneal) done in bulk floatzone (FZ) Si. The $V_{1}^{\text {ex }}$ region ${ }^{4}$ due to the HEI is visible in the window of $0.8-1.6 \mu \mathrm{m}$ for both the SOI and FZ samples. For the SOI an additional Au peak was observed in the region of $\sim 1.6-1.8 \mu \mathrm{m}$. The $V_{1}^{\mathrm{ex}}$ region visible in the FZ Si is not observed after the preanneal. This is a clear indication of the distinctly different kinetics of the processes leading to $V^{\text {ex }}$ removal in the SOI versus the bulk. The exact position of the $\mathrm{Au}$ peak with respect to the BOX was determined by comparing the $\mathrm{Si}$ signal to the $\mathrm{Au}$ in the same RBS spectrum to eliminate variations in the local Si thickness. The inset in Fig. 1(a) compares the Si signal versus the Au signal for the preannealed SOI sample, clearly showing that the Au peak lies in the $\mathrm{Si}$ side of the $\mathrm{Si} / \mathrm{BOX}$ interface.

To determine the nature of the defects that result in $\mathrm{Au}$ trapping at the Si/BOX interface following the Au drive-in, additional interstitials were injected in this interface region via appropriately chosen implant energies followed by annealing. ${ }^{10}$ Less $\mathrm{Au}$ was trapped during Au labeling after interstitial injection, clearly indicating that the defects are

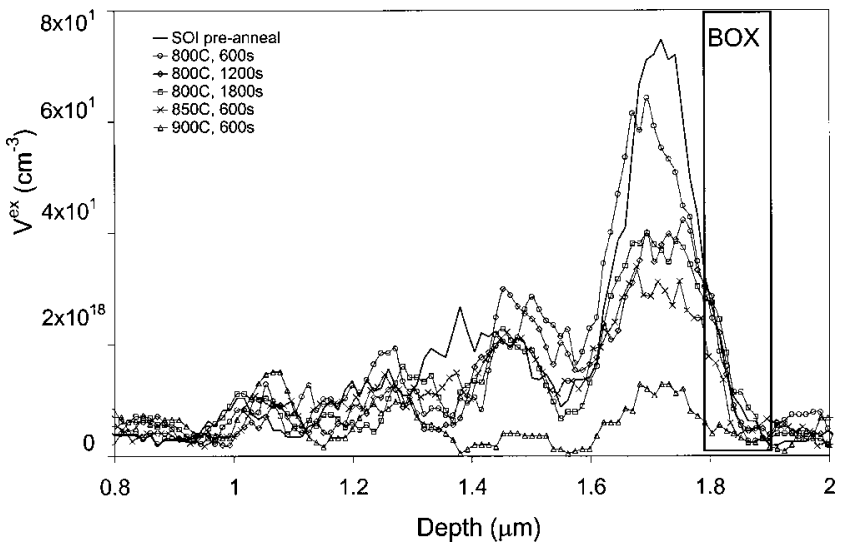

FIG. 2. Time and temperature dependence of $V^{\mathrm{ex}}$.

vacancy type in nature. A similar approach was earlier used to identify the vacancy-type defects and obtain the quantitative relation $k$, between the number of vacancies present to the number of $\mathrm{Au}$ atoms trapped. ${ }^{4}$ The value of $k$ obtained in bulk Si was 1.2 (Ref. 4) and we obtained the same value for the interface. We propose that the cause of this additional vacancy peak is due to the abrupt decrease in density of $\mathrm{Si}$ atoms across the $\mathrm{Si} / \mathrm{BOX}$ interface and the net forward momentum $^{11}$ of the recoiled atoms. Consequently, more atoms are knocked from the Si into the BOX layer than recoil back out of the BOX layer into the $\mathrm{Si}$, resulting in a net deficiency of atoms on the Si side of the interface. This effect is supported by TRIM 98 (Ref. 9) simulations of a $2 \mathrm{MeV}, 2$ $\times 10^{15} \mathrm{~cm}^{-2} \mathrm{Si}$ implant into a $1.5-\mu \mathrm{m}$-thick Si layer on a $0.2-\mu \mathrm{m}$-thick BOX, as seen in Fig. 1(b).

In the subsequent analysis of the thermal behavior of the vacancy clusters, the two distinct $V$ regions between 0.8 and $1.55 \mu \mathrm{m}\left(V_{1}^{\mathrm{ex}}\right)$ and $1.55-1.8 \mu \mathrm{m}\left(V_{2}^{\mathrm{ex}}\right)$ were studied independently. The width of the interface peak, $V_{2}^{\text {ex }}$, in the RBS spectra is a combination of straggle $( \pm 0.04 \mu \mathrm{m})$ in the $\mathrm{He}$ beam, interface roughness, and any thickness variation of the Si device layer within the size of the $\sim 1.5$-mm-diam analysis spot. Figure 2 shows typical $V^{\text {ex }}$ profiles as a function of time and temperature. These profiles were obtained by using the $k$ factor of 1.2 to convert from the measured $\mathrm{Au}$ concentration to the $V^{\mathrm{ex}}$ concentration, $\left(V^{\mathrm{ex}}\right)$. The overall reduction in $\left(V^{\mathrm{ex}}\right)$ with increasing anneal time and/or temperature is evident. To obtain the $E_{b}$ for each region, the evaporation kinetics were measured separately. Figure 3(a) plots the decrease in $\left(V^{\mathrm{ex}}\right)$ as a function of time at each temperature for the $V_{1}^{\mathrm{ex}}$ region (solid legends) and the $V_{2}^{\mathrm{ex}}$ region (open legends). $V^{\text {ex }}$ is expected to decay exponentially with time. Exponential fits of type $V^{\mathrm{ex}}(t)=V^{0} \exp (-t / \tau)$, were used to fit the data for all the temperatures, where $V^{\mathrm{ex}}(t)$ is the $\left(V^{\mathrm{ex}}\right)$ at any time $t, V^{0}$ is the initial concentration (i.e., after the initial $800{ }^{\circ} \mathrm{C}, 600 \mathrm{~s}$ anneal), and $\tau$ is the time constant for vacancy evaporation at each temperature. To determine the $E_{b}$ for the $V^{\text {ex }}$ evaporation, the experimental values for $\tau$ were fitted to an Arrhenius relation $\tau(T)=\tau^{0} \exp \left[\left(E_{b}\right.\right.$ $\left.\left.+E_{m}\right) / k_{b} T\right)$, where $E_{b}$ is the binding energy and $E_{m}$ is migration energy of the vacancy. The fits are shown in Fig. 3(b).

The measured energy for the $V_{1}^{\mathrm{ex}}$ region was $3.5 \pm 0.2 \mathrm{eV}$, while for $V_{?}^{\mathrm{ex}}$ it was $2.9 \pm 0.6 \mathrm{eV} .{ }^{12}$ Using values of $E_{m} \sim 0.3$ 

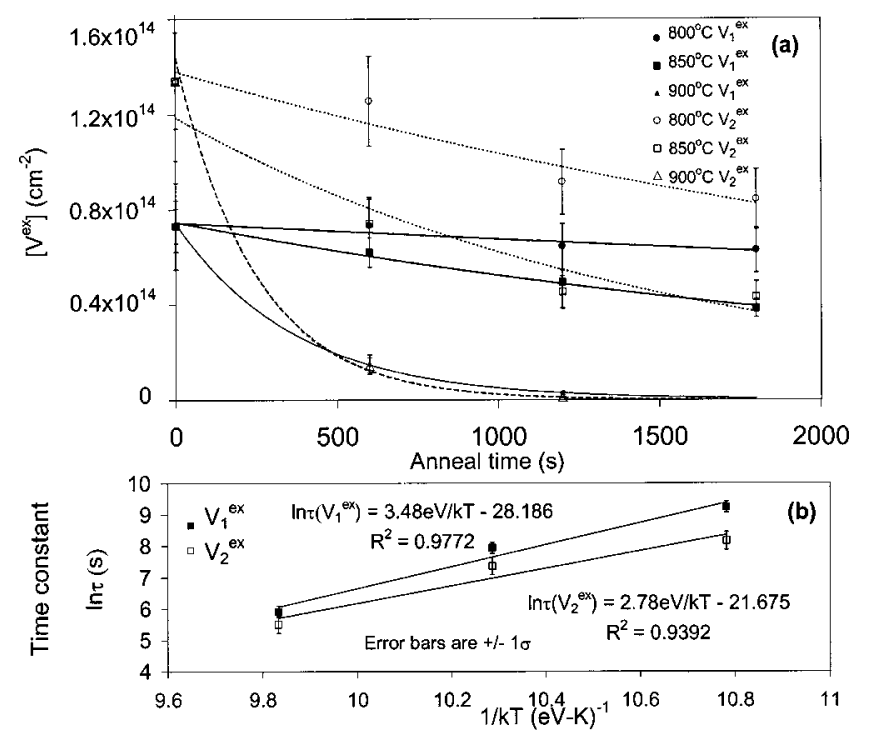

FIG. 3. (a) $\left(V^{\text {ex }}\right)$ vs time in the $V_{1}^{\text {ex }}$ (solid legends) and $V_{2}^{\text {ex }}$ (open legends) regions along with the exponential fits. (b) Time constant $(\tau)$ for $V^{\text {ex }}$ evaporation vs $1 / \mathrm{kT}$ for $V_{1}^{\mathrm{ex}}$ (solid squares) and $V_{2}^{\mathrm{ex}}$ (open squares).

$\mathrm{eV}$ (Ref. 13) binding energies are, respectively, $3.2 \pm 0.2$ and $2.6 \pm 0.6 \mathrm{eV}$ in the two regions. The value for the $V_{1}^{\mathrm{ex}}$ region is consistent with the value of $3.2 \pm 0.5 \mathrm{eV}$ estimated by Venezia et al. ${ }^{14}$ who calculated $E_{b}$ from the measurement of diffusion of $\mathrm{Sb}$ markers in SOI substrates. This number is slightly smaller than the values determined from firstprinciples calculations ${ }^{15}$ or measured by electron paramagnetic resonance. ${ }^{16}$ The slightly smaller value for the vacancy cluster observed here is expected because of the effect of finite cluster size. Chadi and Chang ${ }^{17}$ have estimated via $a b$ initio calculations that on the average, the $E_{b}$ increases with increasing number of vacancies in a cluster.

The time constants measured in the two regions are distinctly different, suggesting that vacancy evaporation is modified near the interface. While $E_{b}$ appears to be lower for clusters near the interface, the large uncertainty in the fits (Fig. 3) precludes a definite conclusion about whether the evaporation mechanism is actually different. The time dependence data in Fig. 3(a) (dashed lines) suggests the possibility of a slowing in the evaporation, as indicated by the relatively small change in going from 1200 to $1800 \mathrm{~s}$ for the 800 and $850^{\circ} \mathrm{C}$ data. This change could be a result of incomplete ripening during the preanneal due to the larger vacancy concentration in the interface region (Fig. 1). Additionally, TRIM simulations ${ }^{10}$ show that a significant concentration of oxygen $\left(\sim 7.3 \times 10^{15} \mathrm{~cm}^{-3}\right)$ is intermixed across the front $\mathrm{Si} / \mathrm{BOX}$ interface. The possible effect of oxygen on the vacancy clusters is not clear. However, it is well known that oxide formation is accompanied by interstitial injection, ${ }^{18}$ which leads to oxidation-induced stacking (OSF) faults. Furthermore, the activation energy for OSF growth is in the range of $\sim 2.3-$ $2.6 \mathrm{eV},{ }^{18}$ which is similar to the activation energy measured in this work for vacancy cluster shrinkage near the Si/BOX region.

In any event, it is clear that the loss of $V^{\text {ex }}$ is not due to interstitial injection from the $\mathrm{BOX}$ or the $R_{p}$ damage. The activation energy for $\mathrm{Si}$ transport through an oxide layer is substantially larger than the activation energy for vacancy loss in the present experiments. Celler and Trimble ${ }^{19}$ measured the activation energy for mass transfer through the oxide to be about $4.4 \mathrm{eV}$, while Tsoukalas, Tsamis, and Stomenos ${ }^{7}$ measured a value of about $4.2 \mathrm{eV}$.

This work highlights the complex nature of defect production in the case of implantation through a buried interface. Two distinct vacancy regions have been identified following the HEI into SOI material. While the $V_{1}^{\text {ex }}$ vacancy region has been identified earlier, ${ }^{1}$ this is a direct measurement of an additional vacancy source at the front Si/BOX interface. The study of the thermal behavior of these two regions clearly shows that the vacancies from the interface region must be accounted for in any processing steps involving implants through the BOX layer. The $E_{b}$ of the vacancies to clusters in the bulk region, as measured using the $V_{1}^{\text {ex }}$ region was estimated to be $3.2 \pm 0.2 \mathrm{eV}$. In comparison, the $E_{b}$ of vacancies to clusters at the interface was smaller, 2.6 $\pm 0.6 \mathrm{eV}$.

The authors are indebted to Cliff King and George Celler for providing the SOI wafers. Research performed at Oak Ridge National Laboratory was sponsored in part by Oak Ridge Associated Universities under Contract No. DEAC05-76OR00033 and by the U.S. Department of Energy, Office of Science, Laboratory Technology Research Division and the Division of Materials Sciences under Contract No. DE-AC05-00OR22725 with UT-Battelle, LLC.

${ }^{1}$ O. W. Holland and C. W. White, Nucl. Instrum. Methods Phys. Res. B 59/60, 353 (1991).

${ }^{2}$ V. C. Venezia, D. J. Eaglesham, T. E. Haynes, A. Agarwal, D. C. Jacobson, H.-J. Gossmann, and F. H. Baumann, Appl. Phys. Lett. 73, 2980 (1998).

${ }^{3}$ V. C. Venezia, T. E. Haynes, A. Agarwal, L. Pelaz, H.-J. Gossmann, D. C. Jacobson, and D. J. Eaglesham, Appl. Phys. Lett. 74, 1299 (1999).

${ }^{4}$ R. Kalyanaraman, T. E. Haynes, V. C. Venezia, D. C. Jacobson, H.-J. Gossmann, and C. S. Rafferty, Appl. Phys. Lett. 76, 3379 (2000).

${ }^{5}$ R. Kalyanaraman, T. E. Haynes, D. C. Jacobson, H.-J. Gossmann, and C. S. Rafferty, Mater. Res. Soc. Symp. Proc. 610, B9.4.1 (2000).

${ }^{6}$ R. Kalyanaraman, T. E. Haynes, D. C. Jacobson, H.-J. L. Gossmann, C. S. Rafferty, and G. H. Gilmer (unpublished).

${ }^{7}$ D. Tsoukalas, C. Tsamis, and J. Stomenos, Appl. Phys. Lett. 63, 3167 (1993).

${ }^{8}$ R. Kalyanaraman, T. E. Haynes, M. Yoon, B. C. Larson, D. C. Jacobson, H.-J. L. Gossmann, and C. S. Rafferty, Nucl. Instrum. Methods Phys. Res. B 175-177, 182 (2001).

${ }^{9}$ J. F. Ziegler, J. P. Biersack, and U. Littmark, The Stopping and Ranges of Ions in Solids (Pergamon, New York, 1985).

${ }^{10}$ R. Kalyanaraman, T. E. Haynes, H.-J. L. Gossman, C. S. Rafferty, and G. H. Gilmer, presented at the MRS Spring meeting 2001, in Symposium J, Si Front-End Processing, Physics and Technology of Dopant-Defect Interactions III, April 16-20, San Francisco, CA (unpublished).

${ }^{11}$ A. M. Mazzone, Phys. Status Solidi A 95, 149 (1986).

${ }^{12}$ Statistical uncertainty in $(\mathrm{Au})$ measurement and standard error propagation was used to determine the uncertainties in the binding energies; for example, see R. Bevington, Data Reduction and Error Analysis for the Physical Sciences (McGraw-Hill, New York, 1969).

${ }^{13}$ G. D. Watkins, J. R. Troxell, and A. P. Chatterjee, Inst. Phys. Conf. Ser. 46, 16 (1979).

${ }^{14}$ V. C. Venezia, L. Pelaz, H.-J. Gossmann, T. E. Haynes, and C. S. Rafferty, Appl. Phys. Lett. (submitted).

${ }^{15}$ C. S. Nichols, C. G. Van de Walle, and S. T. Pantelides, Phys. Rev. Lett. 62, 1049 (1989).

${ }^{16}$ G. D. Watkins and J. W. Corbett, Phys. Rev. 134, A1359 (1964).

${ }^{17}$ D. J. Chadi and K. J. Chang, Phys. Rev. B 38, 1523 (1988).

${ }^{18}$ S. M. Hu, Mater. Sci. Eng., R. R13, 105 (1994).

${ }^{19}$ G. K. Celler and L. E. Trimble, Appl. Surf. Sci. 39, 245 (1989). 
(This page intentionally left blank.) 


\title{
Enhanced low temperature electrical activation of $\mathrm{B}$ in $\mathrm{Si}$
}

\author{
Ramki Kalyanaraman ${ }^{\text {a) }}$ \\ Solid State Division, Oak Ridge National Laboratory, Oak Ridge, Tennessee 37831 and Agere Systems, \\ Murray Hill, New Jersey 079743 and Washington University in St. Louis, St. Louis, Missouri 63130 \\ V. C. Venezia \\ Phillips Royal Electronics, IMEC, Leuven, Belgium \\ L. Pelaz \\ University de Valladolid, Valladolid, Spain 47011 \\ T. E. Haynes \\ Solid State Division, Oak Ridge National Laboratory, Oak Ridge, Tennessee 37831 \\ H.-J. L. Gossmann and C. S. Rafferty \\ Agere Systems, Murray Hill, New Jersey 07974
}

(Received 7 October 2002; accepted 14 November 2002)

\begin{abstract}
The electrical activation of $\mathrm{B}$ in $n$-type epitaxial-Si(100) has been enhanced in the temperature range of $400-800^{\circ} \mathrm{C}$. This enhanced activation was measured for $40 \mathrm{keV}, 2 \times 10^{14} \mathrm{~cm}^{-2}$ dose of $\mathrm{B}$ implanted into a vacancy-rich Si region. The vacancy-rich region consists of excess vacancies $\left(V^{\mathrm{ex}}\right)$ generated by a $2 \mathrm{MeV}$ Si implant in the dose range of $3 \times 10^{15}-10 \times 10^{15} \mathrm{~cm}^{-2}$. The B activation in vacancy-rich $\mathrm{Si}$ is found to be a factor of $\sim 2.4$ larger with up to $\sim 80 \%$ of the B activated as compared to similar B implant and activation anneals carried out in the bulk Si. The dependence of B activation on $V^{\mathrm{ex}}$ concentration shows that the active B concentration increases with the $V^{\mathrm{ex}}$ concentration. From this dependence it was estimated that at least three vacancies are required to activate an additional B atom. This process is distinctly different from the low temperature activation that occurs during solid-phase epitaxial recrystallization of B-doped amorphous Si as no amorphous $\mathrm{Si}$ is produced during any step. This low temperature processing will be advantageous in situations where the epitaxial recrystallization of a doped amorphous Si layer is not possible, for instance in the fabrication of fully depleted Si-on-insulator devices. (c) 2003 American Institute of Physics. [DOI: $10.1063 / 1.1535270]$
\end{abstract}

The ability to activate dopants in Si at ever lower temperatures will continue to be a motivating challenge for shallow-junction researchers. A lower process temperature implies a reduction in the thermal budget and ultimately in the cost of manufacturing. Currently the lowest possible anneal temperature that can electrically activate B in $\mathrm{Si}$ with reasonable thermal budgets occurs when an amorphized $\mathrm{Si}$ region containing a suitable amount of B is recrystallized. ${ }^{1}$ The recrystallization temperatures can be as low as $600{ }^{\circ} \mathrm{C}^{2}$ with $\sim 100 \%$ of B being activated in the dose range up to $\sim 10^{16} \mathrm{~cm}^{-2}$. However, this approach is unsuitable for situations when the active device layer can extend all the way to a substrate other than single crystal Si. One example is the increasing use of fully depleted Si-on-insulator (SOI) devices, ${ }^{3}$ where the device layer extends to the insulating substrate. Under these conditions, the regrowth of a singlecrystal Si overlayer from amorphous conditions does not occur because of the lack of a suitable seed layer.

For the case of $\mathrm{B}$, it is now well accepted that lowtemperature activation in crystalline $\mathrm{Si}^{4}$ is limited by the formation of B clusters, ${ }^{5}$ even below the B solubility limit. While the exact details of the clustering process are still unclear, a common theme in the numerous models is the presence of the large concentration of interstitials $(I)$ following

${ }^{a)}$ Electronic mail: ramkik@wuphys.wustll.edu the implantation step in crystalline Si. Prior work has clearly shown that the interstitial supersaturations are reduced by excess vacancies from high-energy implants. ${ }^{6}$ In this work, we deliberately implanted $\mathrm{B}$ into $\mathrm{Si}$ regions containing a large supersaturation of vacancies $(V)$ and subsequently measured the electrical behavior.

Previous work on using high-energy implantation (HEI) to modify the B shallow-junction properties clearly show a reduction in transient enhanced diffusion and subsequently, shallower junctions. ${ }^{7}$ However, previous attempts to enhance the B electrical activation using high-energy ion implantation have been unsuccessful. ${ }^{8}$ Both, Saito et al., and Larsen et al., utilized mega-electron-volt implantation. Also, in both these studies, the $\mathrm{B}$ atoms resided in an amorphous $\mathrm{Si}$ layer and no increase in electrical activity of B was reported.

In the last few years we have extensively characterized ${ }^{9}$ and quantitatively studied the production of excess vacancies $\left(V^{\mathrm{ex}}\right)$ following HEI into $\mathrm{Si}^{10}{ }^{10}$ Specifically we have observed a large concentration of $V^{\mathrm{ex}}$ near the surface ${ }^{11}$ and in the regions around half the projected range $\left(1 / 2 R_{p}\right)$ of the HEI implants. In this work we use the large near-surface $V^{\text {ex }}$ concentration to enhance the electrical activation of $\mathrm{B}$. This approach produces an active B concentration of up to $80 \%$ of the implanted dose $\left(2 \times 10^{14} \mathrm{~cm}^{-2}\right)$ in the temperature range of $400-800^{\circ} \mathrm{C}$, which is a factor of $\sim 2.4$ times greater than that achieved without HEI. 


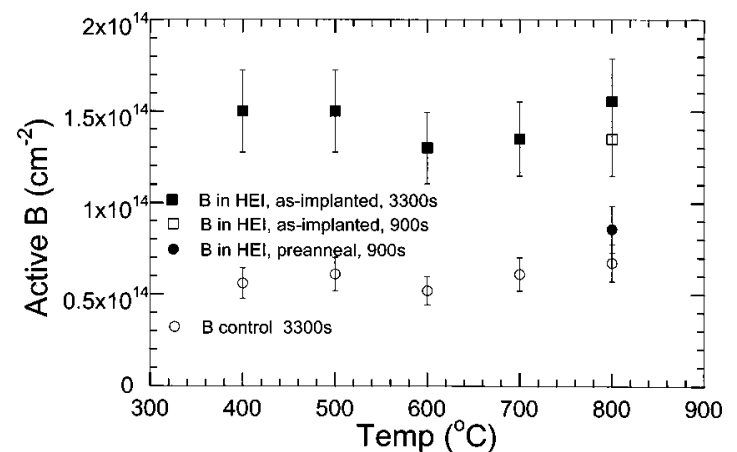

FIG. 1. The integrated active B concentration for $10 \times 10^{15} \mathrm{~cm}^{-2}$ in asimplanted HEI (solid squares) as a function of anneal $T$ after $3300 \mathrm{~s}$ activation anneals. The B control (i.e., no HEI) is shown in open circles. Also shown are measurements of the active B following a $900 \mathrm{~s}$ anneal in the as-implanted HEI (open square) and HEI containing a preanneal at $815^{\circ} \mathrm{C}$ for $900 \mathrm{~s}$ (solid circle). The uncertainty in the measurement is $\pm 15 \%$.

The production and measurement of the $V^{\text {ex }}$ profile follows the approach reported in detail in earlier publications. ${ }^{11,12}$ Briefly, $2 \mathrm{MeV}{ }^{28} \mathrm{Si}+$ ions are implanted into $n$-type epi-Si(100) $(\rho \sim 0.15 \Omega \mathrm{cm})$ or $p$-type floating, zone (FZ) $-\operatorname{Si}(100)(\rho \sim 85 \Omega \mathrm{cm})$. The substrate temperature was maintained at $70^{\circ} \mathrm{C}$ during the implant, while the implanted dose varied from $3 \times 10^{15} \mathrm{~cm}^{-2}$ to 10 $\times 10^{15} \mathrm{~cm}^{-2}$. The ion current used was typically $0.5 \mu \mathrm{A} / \mathrm{cm}^{2}$ and under these conditions no amorphization of $\mathrm{Si}$ takes place. ${ }^{13}$ High-resolution transmission electron microscopy on the highest dose samples confirmed that the implanted layer was devoid of amorphous regions. These conditions produce a $V^{\mathrm{ex}}$ rich region which extends from the surface to near the projected range $\left(R_{p}\right) .{ }^{14}$

We measured the $V^{\text {ex }}$ quantitatively by the Au labeling technique. ${ }^{15}$ The technique consists of producing a surface source of $\mathrm{Au}$ by implanting sufficient $\mathrm{Au}$ (here $\sim 8$ $\times 10^{14} \mathrm{~cm}^{-2}$ ) at $68 \mathrm{keV}$ into the HEI samples followed by a drive-in anneal at $750{ }^{\circ} \mathrm{C}$ to interact the Au with the $V^{\text {ex }}$. Following this, the Au concentration as a function of depth is measured, typically by Rutherford backscattering (RBS). Using the calibration factor ${ }^{15} k=1.2$, relating the concentration of $[\mathrm{Au}]$ to $\left[V^{\mathrm{ex}}\right]$ as $\left[V^{\mathrm{ex}}\right]=k[\mathrm{Au}]$, the concentration of $V^{\mathrm{ex}}$ is then determined.

In this work, a ${ }^{10} \mathrm{~B}$ implant of $2 \times 10^{14} \mathrm{~cm}^{-2}$ dose $^{16}$ and $40 \mathrm{keV}$ energy (projected range, $R_{p}$, of $\left.\sim 0.14 \mu \mathrm{m}\right)^{17}$ was implanted at room temperature at a current density of 0.1 $\mu \mathrm{A} / \mathrm{cm}^{2}$. These conditions do not amorphize $\mathrm{Si}^{18}{ }^{18} \mathrm{~B}$ was implanted into the as-implanted HEI samples. A set of experimental control samples was produced by performing identical B implants into bulk Si samples without HEI. Activation anneals were performed in the temperature range of 400$800{ }^{\circ} \mathrm{C}$ in $\mathrm{Ar}$ atmospheres for either 900 or 3300 s. Subsequently, the electrical activation was measured by spreading resistance profiling. ${ }^{19}$ All the implants and RBS measurements were performed using the $1.7 \mathrm{MeV}$ tandem accelerator at Agere Systems, Murray Hill, NJ or Oak Ridge National Laboratory, Oak Ridge, TN.

Figure 1 compares the electrically active $\mathrm{B}$ concentration in the $T$ range of $400-800{ }^{\circ} \mathrm{C}$ after a $3300 \mathrm{~s}$ anneal in epi-Si with (solid squares) and without (open circles) the 10 $\times 10^{15} \mathrm{~cm}^{-2}$ Si HEI. While the concentration of active B is between 1.3 and $1.6 \times 10^{14} \mathrm{~cm}^{-2}(\sim 65 \%-80 \%)$ for the HEI

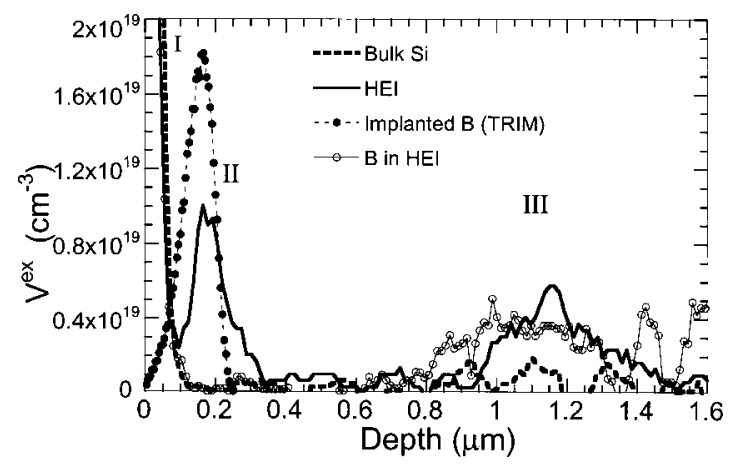

FIG. 2. The $V^{\mathrm{ex}}$ profile in epi-Si obtained via $\mathrm{Au}$ labeling for the 10 $\times 10^{15} \mathrm{~cm}^{-2}$ HEI sample (solid line) and in bulk-Si (no HEI-dashed line). The implanted $\mathrm{Au}(\mathrm{I})$, near-surface $V^{\mathrm{ex}}$ (II) and $1 / 2 R p V^{\mathrm{ex}}$ (III) regions are indicated. The $V^{\text {ex }}$ profile following the B implant and $900 \mathrm{~s}$ anneal in the HEI sample is indicated by the open circle. The location of the B implant as estimated using TRIM is identified by the solid circle. The annihilation of the region II $V^{\mathrm{ex}}$ is clearly visible for the B in the HEI curve (open circles).

samples, it lies between 0.56 and $0.65 \times 10^{14} \mathrm{~cm}^{-2}(\sim 28-$ $33 \%)$ for the controls. This is an increase by up to a factor of $\sim 2.3-2.4$ for the whole temperature range studied (no activation was noted in control samples containing only the HEI). Further, this figure shows that almost $75 \%$ of the B in HEI is activated at $400{ }^{\circ} \mathrm{C}$, without producing any amorphous regions. While the overall trend of the two curves are very similar possibly indicating reverse annealing ${ }^{4}$ behavior in the temperature range of $500-600^{\circ} \mathrm{C}$ for the HEI case, the measurement error of $\pm 15 \%$ prohibits a conclusive comparison.

We also observed that the state of the supersaturated vacancies prior to the B implant and anneal was important. It has been observed earlier that annealing of the HEI sample results in the clustering of vacancies in the $V$ supersaturated regions. ${ }^{13,20}$ Figure 1 shows that the activated B concentration following a $900 \mathrm{~s}$ anneal was higher in the as-implanted HEI (open square $\sim 1.4 \times 10^{14} \mathrm{~cm}^{-2}$ ) then in the HEI containing a prior annealing step (solid circle $\sim 0.86$ $\times 10^{13} \mathrm{~cm}^{-2}$ ). This HEI sample was annealed at $815^{\circ} \mathrm{C}$ for $900 \mathrm{~s}$ in Ar. This result suggests that the vacancy clusters may be less effective in preventing $\mathrm{B}$ clustering or making the B substitutional.

Figure 2 shows $V^{\text {ex }}$ profiles following the 10 $\times 10^{15} \mathrm{~cm}^{-2}$ dose HEI and subsequent B implantation and annealing, as measured by Au labeling. The $V^{\mathrm{ex}}$ profile in the as-implanted HEI is shown by the solid line while the $\mathrm{Au}$ profile in bulk-Si (no HEI) is shown by the dashed line. Three distinct regions, discussed previously in Ref. 11, are visible for the HEI sample (I). The implanted Au from the surface down to $0.1 \mu \mathrm{m}$, (II) a near surface $V^{\text {ex }}$ region of which the interval from 0.1 to $0.4 \mu \mathrm{m}$ is visible under these experimental conditions, and (III) the $V^{\text {ex }}$ region in the depth of 0.5-1.6 $\mu \mathrm{m}$. The $V^{\text {ex }}$ profile following B implant and anneal $(900 \mathrm{~s})$ in the HEI is shown by the curve with open circles. The annihilation of vacancies in region II is clearly visible. The location of this annihilation corresponds to the implanted B profile (solid circle), as estimated using transport of ions in matter (TRIM). ${ }^{17}$

In Fig. 2, information of the total spatial extent of the near surface $V^{\text {ex }}$ is destroyed because of the Au implant. However, we have confirmed that the near-surface $V^{\mathrm{ex}}$ ex- 


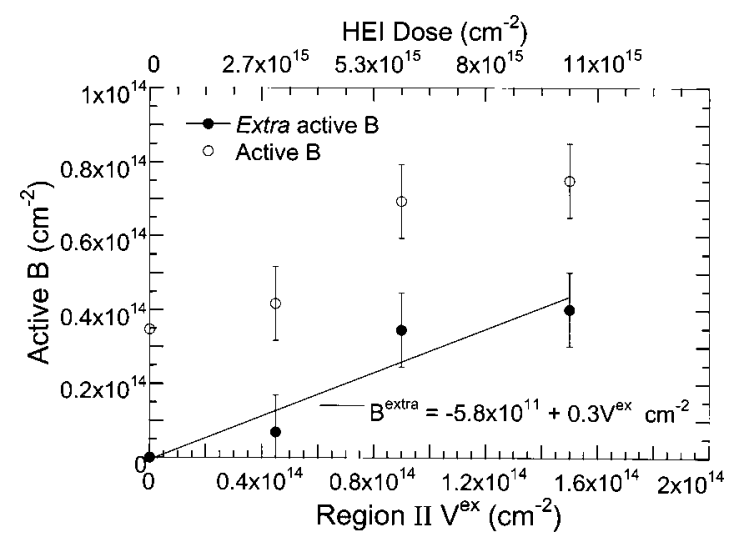

FIG. 3. The integrated active $\mathrm{B}$ in FZ-Si as a function of the HEI dose (open circles) following $3300 \mathrm{~s}$ activation anneals. The closed circles show the extra active B atoms as a function of the integrated region II $V^{\text {ex }}$ (depth interval of $0.1-0.4 \mu \mathrm{m}$ ) obtained for the FZ-Si wafers. The linear dependence of the extra active $\mathrm{B}$ on the $V^{\mathrm{ex}}$ concentration suggest that at least three vacancies are required. The standard deviation error in the measurement of the $V^{\mathrm{ex}}$ concentration was estimated to be about $\pm 9 \times 10^{12} \mathrm{~cm}^{-2}$.

tends from the surface to about $0.4 \mu \mathrm{m}$. To do this, we carried out molecular beam epitaxy growth of a $0.3-\mu \mathrm{m}$-thick $\mathrm{Si}$ layer on a sample containing $10 \times 10^{15} \mathrm{~cm}^{-2}$ dose of $2 \mathrm{MeV}$ $\mathrm{Si}$, so as to move the original surface deeper in. Subsequent Au labeling showed that the $V^{\text {ex }}$ profile extended from the original surface.

The dose dependence was observed in $p$-type $\mathrm{FZ}-\mathrm{Si}$ samples. The B activation anneal was performed at $700{ }^{\circ} \mathrm{C}$ for $3300 \mathrm{~s}$. Figure 3 plots the active B (open circles) as a function of the HEI dose (with the control having no HEI dose). As seen, the active B increases with the HEI dose. While increasing the HEI dose increases the $V^{\text {ex }}$ concentration in region II, as discussed in the previous paragraph, an accurate dependence between the number of extra B atoms (i.e., above the value in the control $\mathrm{Si}$ ) activated and the near surface (region II) $V^{\text {ex }}$ is not possible. However, an upper limit for the efficiency of the $V$ in activating $\mathrm{B}$ can be estimated by the integral $V$ concentration observed in region II (in the interval of $0.1-0.4 \mu \mathrm{m}$ ). Figure 3 plots the number of extra B atoms (closed circles) activated against the integral region II $V^{\mathrm{ex}}$ obtained for FZ-Si in the HEI dose range of $3 \times 10^{15}-10 \times 10^{15} \mathrm{~cm}^{-2}$. A linear increase is observed in the number of activated $\mathrm{B}$ atoms with a slope of 0.3 . This suggests that at least $\sim 3$ vacancies are required to activate an extra B atom.

The present process differs fundamentally from the earlier attempts mentioned previously ${ }^{8}$ in that no amorphous $\mathrm{Si}$ layer is formed. This therefore allows the possibility that the implanted B and/or the interstitials can interact with the large vacancy concentrations in crystalline Si.

In summary, the electrical activity of B in Si was studied in $n$-type epi-Si and $p$-type FZ-Si wafers implanted with 2 $\mathrm{MeV}$ Si. We have observed an increased electrical activation of B implanted into a region containing a large vacancy concentration. An increase by up to a factor of $\sim 2.4$ in active B concentration was observed in the temperature range of 400$800^{\circ} \mathrm{C}$. The state of the vacancies prior to the $\mathrm{B}$ activation anneal was also seen to influence the amount of active B: pre-annealing at $815^{\circ} \mathrm{C}$ to form vacancy clusters reduced the activation enhancement. In addition, we observed that the concentration of electrically active B increases with an increase in the concentration of vacancies. A lower limit on the number of vacancies required to increase the $\mathrm{B}$ activation over the control was found to be three vacancies for every extra B atom. The efficiency of the $V^{\text {ex }}$ region in enhancing $\mathrm{B}$ activation was found to be similar for the epi and $\mathrm{FZ}-\mathrm{Si}$ for $10 \times 10^{15} \mathrm{~cm}^{-2}$ Si HEI samples, even though the overall active B concentration was lower for the FZ sample. The results in this work show that it is possible to achieve a high concentration of electrically active B at low temperatures without amorphizing Si. This makes it suitable for situations where amorphization and recrystallization is not possible, as for example in processes for fully depleted SOI.

Research performed at Oak Ridge National Laboratory was sponsored in part by Oak Ridge Associated Universities under Contract No. DE-AC05-76OR00033 and by the U.S. Department of Energy, Office of Science, Laboratory Technology Research Division and the Division of Materials Sciences under Contract No. DE-AC05-00OR22725 with UTBattelle, LLC.

${ }^{1}$ W. L. Crowder, J. Electrochem. Soc. 118, 943 (1971).

${ }^{2}$ D. E. Davies, Appl. Phys. Lett. 14, 227 (1969).

${ }^{3}$ S. W. Crowder, P. M. Rousseau, J. P. Snyder, J. A. Scott, P. B. Griffen, and J. D. Plummer, IEEE International Electron Devices Meeting Proceedings, 1995, pp. 95-427; D. Monroe and J. M. Hergenrother, IEEE International SOI Conference Proceedings, 1998, p. 157.

${ }^{4}$ T. Seidel and A. U. MacRae, Proceedings of First Int. Conference In Ion Implantation (Gordon and Breach, New York, 1971), p. 253.

${ }^{5}$ N. E. B. Cowern, H. F. F. Jos, and K. T. F. Janssen, J. Appl. Phys. 68, 6191 (1990); P. A. Stolk, H.-J. Gossmann, D. J. Eaglesham, D. C. Jacobson, and J. M. Poate, Appl. Phys. Lett. 70, 2285 (1997).

${ }^{6}$ V. C. Venezia, T. E. Haynes, A. Agarwal, L. Pelaz, H.-J. Gossmann, D. C. Jacobson, and D. J. Eaglesham, Appl. Phys. Lett. 74, 1299 (1999).

${ }^{7}$ V. Raineri, R. J. Schreutelkamp, F. W. Saris, K. T. F. Jansen, and R. E. Kaim, Appl. Phys. Lett. 58, 922 (1991); E. G. Roth, O. W. Holland, V. C. Venezia, and B. Nielsen, J. Electron. Mater. 26, 1349 (1997); L. Shao, X. Lu, X. Wang, I. Rusakova, J. Liu, and W.-K. Chu, Appl. Phys. Lett. 78, $2321(2001)$

${ }^{8}$ S. Saito, M. Kumagai, and T. Kondo, Appl. Phys. Lett. 63, 197 (1993); K. K. Larsen, V. Privitera, S. Coffa, F. Priolo, C. Spinella, M. Saggio, and S. U. Campisano, Nucl. Instrum. Methods Phys. Res. B 112, 139 (1996).

${ }^{9}$ R. Kalyanaraman, T. E. Haynes, D. C. Jacobson, H.-J. Gossmann, and C. S. Rafferty, Mater. Res. Soc. Symp. Proc. 610, B9.4.1 (2000).

${ }^{10}$ R. Kalyanaraman, T. E. Haynes, O. W. Holland, and G. H. Gilmer, J. Appl. Phys. 91, 6325 (2002).

${ }^{11}$ V. C. Venezia, D. J. Eaglesham, T. E. Haynes, A. Agarwal, D. C. Jacobson, H.-J. Gossmann, and F. H. Baumann, Appl. Phys. Lett. 73, 2980 (1998).

${ }^{12}$ R. Kalyanaraman, T. E. Haynes, V. C. Venezia, D. C. Jacobson, H.-J. Gossmann, and C. S. Rafferty, Mater. Res. Soc. Symp. Proc. 610, B9.2.1 (2000).

${ }^{13}$ V. C. Venezia, Ph.D. thesis, University of North Texas, Denton, Texas, May 1999.

${ }^{14}$ O. W. Holland and C. W. White, Nucl. Instrum. Methods Phys. Res. B 59/60, 353 (1991); C. Szeles, B. Nielsen, P. Asoka-Kumar, K. G. Lynn, M. Anderle, T. P. Ma, and G. W. Rubloff, J. Appl. Phys. 76, 3403 (1994); S. L. Ellingboe and M. C. Ridgway, Nucl. Instrum. Methods Phys. Res. B 127, 128, 90 (1997)

${ }^{15}$ R. Kalyanaraman, T. E. Haynes, V. C. Venezia, D. C. Jacobson, H.-J. Gossmann, and C. S. Rafferty, Appl. Phys. Lett. 76, 3379 (2000).

${ }^{16}$ L. Pelaz, V. C. Venezia, H.-J. Gossmann, G. H. Gilmer, A. T. Fiory, C. S. Rafferty, M. Jaraiz, and J. Barbolla, Appl. Phys. Lett. 75, 662 (1999).

${ }^{17}$ J. F. Ziegler, J. P. Biersack, and U. Littmark, The Stopping and Ranges of Ions in Solids (Pergamon, New York, 1985).

${ }^{18}$ J. Narayan and O. W. Holland, J. Electrochem. Soc. 131, 2651 (1984).

${ }^{19}$ Solecon Laboratories, Inc., San Jose, California.

${ }^{20}$ R. Kalyanaraman, T. E. Haynes, O. W. Holland, H.-J. L. Gossmann, C. S. Rafferty, and G. H. Gilmer, Appl. Phys. Lett. 79, 1983 (2001). 
(This page intentionally left blank.) 


\title{
Character of defects at an ion-irradiated buried thin-film interface
}

\author{
R. Kalyanaraman ${ }^{\text {a) }}$ \\ Oak Ridge National Laboratory, Oak Ridge, Tennessee 37831; \\ Agere System, 700 Mountain Avenue, Murray Hill, New Jersey 07974; \\ and Department of Physics, Washington University, St. Louis, Missouri 63130
}

T. E. Haynes and O. W. Holland

Oak Ridge National Laboratory, Oak Ridge, Tennessee 37831

G. H. Gilmer ${ }^{\text {b) }}$

Agere System, 700 Mountain Avenue, Murray Hill, New Jersey 07974

(Received 1 October 2001; accepted for publication 25 February 2002)

\begin{abstract}
In order to investigate the nature of defects produced by ion irradiation through a heterostructure, a silicon-on-insulator substrate with a buried $\mathrm{SiO}_{2}$ layer at a depth of $\sim 1.5 \mu \mathrm{m}$ was irradiated. The implantation was done using $2 \mathrm{MeV}{ }^{28} \mathrm{Si}^{+}$ions in the dose range of $0.2-1 \times 10^{16} \mathrm{~cm}^{-2}$. The subsequent defect analysis was performed using the Au labeling technique. Besides the presence of an expected excess of vacancy-type defects in the $\operatorname{Si}$ overlayer $\left(V_{\mathrm{Si}}^{\mathrm{ex}}\right)$, an additional vacancy excess peak was observed at the frontside of the buried interface $\left(V_{\mathrm{Int}}^{\mathrm{ex}}\right)$. The $V_{\mathrm{Int}}^{\mathrm{ex}}$ is found to increase linearly with increasing dose of the high-energy implant. The presence of this $V_{\mathrm{Int}}^{\mathrm{ex}}$ peak near the interface is also predicted by the TRIM Monte Carlo code. Additional Monte Carlo simulations of damage production via high-energy implantation in $\mathrm{Si} / X$-type structures show that the nature of the defects at the front $\mathrm{Si} / X$ interface can be changed from vacancy to interstitial-type by increasing the mass of atoms in the buried thin-film, $X$. These experiments provide quantitative verification of nonuniform defect production at an ion-irradiated buried interface in Si. (C) 2002 American Institute of Physics. [DOI: 10.1063/1.1470258]
\end{abstract}

\section{INTRODUCTION}

In recent times, the idea of integrating different materials with $\mathrm{Si}$ and other substrates has grown in importance due to the tremendous potential to make sophisticated devices. The integrated materials approach can lead to structures with opto-, electro-, and mechanical abilities coupled onto a single chip. ${ }^{1}$ This obviously attractive possibility brings with it a number of processing complications, among which thermal expansion mismatch ${ }^{2}$ and the presence of the numerous interfaces are particularly important. The presence of thermal expansion mismatches will be manifest in any thermal treatments of the integrated structures, while the interfaces will appear in the coupling of properties between the various layers.

In this view, postprocessing of the structures to control strain and interface properties will require techniques that are capable of a spatial deposition of energy as well as mass. Ion implantation is the primary technique for such situations. It can be used to modify bulk as well as interfacial properties, via doping, intermixing, etc. In fact, one of the most extensively studied problems is that of radiation-induced mixing across interfaces. Numerous books ${ }^{3}$ and review articles ${ }^{4}$ are available on the topic of ion-beam mixing of interfaces and buried thin films. However, these studies have typically relied on the detection of interfacial intermixing via spectro-

\footnotetext{
a)Electronic mail: ramkik@wuphys.wustl.edu

b) Present address: Lawrence Livermore National Laboratory, Livermore, CA 94550 .
}

metric techniques like Rutherford backscattering (RBS) or secondary ion mass spectrometry (SIMS). The direct quantitative detection of interstitials and vacancies has been difficult. Numerous techniques have been used to profile point defects following implantation. For example, positron annihilation spectroscopy, ${ }^{5}$ ion channeling, ${ }^{6}$ impurity-defect interaction profiling, ${ }^{7}$ Raman spectroscopy,${ }^{8}$ etc. The most reliable quantitative technique for studying interstitials, particularly for $\mathrm{Si}$, has been via the growth of interstitial clusters $^{9}$ or via the behavior of dopants known to diffuse by interstitial mechanisms. ${ }^{10,11}$ In comparison, the quantitative study of vacancies in $\mathrm{Si}$ is even more difficult. ${ }^{12}$ However, recently we have calibrated the Au labeling technique ${ }^{13}$ and used it to make a number of quantitative measurements of $V^{\text {ex }}$ generation in $\mathrm{Si}$ from high-energy ion (HEI) implantation. ${ }^{14}$ In this work, we use the Au labeling technique to detect and quantitatively study the production of $V$-type defects near the front interface of a buried $\mathrm{SiO}_{2}$ thin film in $\mathrm{Si}$ after implantation by $2 \mathrm{MeV}{ }^{28} \mathrm{Si}^{+}$. We also used the Monte Carlo simulation code TRIM (Ref. 15) to observe the nature of the excess defects at the buried $\mathrm{Si} / \mathrm{SiO}_{2}$ interface. Monte Carlo simulations also show that for structures of type $\mathrm{Si} / X$, the mass of atoms in the thin-film $X$ strongly influences the concentration of the excess defect (i.e., $I$ or $V$ type) at the front interface. The simulations suggest that not only the concentration but also the type of defect ( $I$ or $V$ type) at the interface can be controlled by an appropriate choice of mass of the buried layer, affording a possible approach to control strain in overlayers. 


\section{EXPERIMENT}

The silicon-on-insulator (SOI) wafer used in this work had an approximately $1.5-\mu$ m-thick top $\mathrm{Si}$ layer, while the buried $\mathrm{SiO}_{2}$ thin film was $0.2 \mu \mathrm{m}$ thick. The thick $\mathrm{Si}$ top layer was prepared by rapid thermal chemical vapor deposition of a $\sim 1.3-\mu$ m-thick Si layer on commercially available bonded SOI having a $0.2 \mu \mathrm{m}$ silicon $p / p^{+}$epi-Si top layer. The substrate below the buried oxide (BOX) was Czochralski silicon. The final $1.5 \pm 0.2-\mu \mathrm{m}$-thick $\mathrm{Si}$ was nominally undoped and the background $\mathrm{O}$ and $\mathrm{C}$ concentrations were below the SIMS detection limits of $\sim 5 \times 10^{17}$ and $\sim 5$ $\times 10^{16} \mathrm{~cm}^{-3}$, respectively. Cross-sectional transmission electron microscopy (TEM) analysis of the as-grown wafer did not reveal any bulk or interfacial defects. The HEI implantation through the $\mathrm{SiO}_{2}$ layer was achieved by implanting $2 \mathrm{MeV}{ }^{28} \mathrm{Si}^{+}$in the dose range of $0.2-1 \times 10^{16} \mathrm{~cm}^{-2}$ using a National Electrostatics Pelletron accelerator at an angle of $7^{\circ}$ to the substrate normal. The beam current was $1.4 \mu \mathrm{A}$ while the substrate temperature was held at $70^{\circ} \mathrm{C}$ to prevent amorphization. Since the projected range $\left(R_{p}\right)$ of the $2 \mathrm{MeV}$ Si implant is $\sim 2 \mu \mathrm{m}$ with a straggle of $\sim 0.25 \mu \mathrm{m}$ [as calculated from TRIM98 (Ref. 16)] the interstitial-type defect is behind the $\mathrm{SiO}_{2}$ layer.

Previously, $V$-type defects have been probed by a second Si implant of suitably chosen energy such that the $R_{p}$ of this implant lies in the region of the vacancies. ${ }^{13,17} \mathrm{~A}$ suitably chosen heat treatment then induces recombination between the vacancies and injected interstitials. Here, $\mathrm{Si}$ was implanted in the interface region of the $1 \times 10^{16} \mathrm{~cm}^{-2}$ dose HEI sample with energies of $1.15\left(R_{p} \sim 1.41 \mu \mathrm{m}\right), 1.3\left(R_{p}\right.$ $\sim 1.52 \mu \mathrm{m})$, or $1.5 \mathrm{MeV}\left(R_{p} \sim 1.66 \mu \mathrm{m}\right)$. The energy was varied slightly to compensate for any variation in the depth of the $\mathrm{Si} / \mathrm{SiO}_{2}$ interface as well as to control the number of $\mathrm{Si}$ atoms implanted near the interface. The areal density of the implanted $\mathrm{Si}$ atoms in the $\mathrm{Si}$ region near the interface was determined by measuring the position of the interface via RBS and then integrating the area up to the interface under the simulated implanted profile as determined by TRIM98. These samples were then annealed at $760^{\circ} \mathrm{C}$ for $1020 \mathrm{~s}$ in a tube furnace under $1 \mathrm{~atm}$ of Ar (flow rate of $1.5 \mathrm{lpm}$ ). Depending upon the nature of the preexisting defects near the interface, this anneal will either grow interstitial clusters or recombine the added $\mathrm{Si}$ atoms with any existing $V$-type defects. The defect production in the SOI wafers was compared with bulk $\mathrm{Si}(100)$ wafers of float-zone type (FZ), where the identical $2 \mathrm{MeV} \mathrm{Si}$ implant in the dose range of $0.2-1$ $\times 10^{16} \mathrm{~cm}^{-2} \mathrm{Si}$ was carried out.

Finally, the vacancy defect profiles were measured using Au labeling ${ }^{18}$ by implanting $68 \mathrm{keV}{ }^{196} \mathrm{Au}^{+}$at a dose of 8 $\times 10^{14} \mathrm{~cm}^{-2}$ followed by a drive-in anneal at $750{ }^{\circ} \mathrm{C}$ (in 1 atm Ar with flow rate of $1.5 \mathrm{lpm})$. The anneal was performed until the saturation of $\mathrm{Au}$ in the $V^{\mathrm{ex}}$ region. ${ }^{19}$ Rutherford backscattering using $2.8-3.0 \mathrm{MeV}{ }^{4} \mathrm{He}^{2+}$ was performed to measure the resulting Au profiles. Calibration experiments reported previously ${ }^{13}$ have shown that under these HEI implant conditions the $V^{\mathrm{ex}}$ concentration is equal to the $\mathrm{Au}$ concentration multiplied by the calibration factor $k=1.2$.
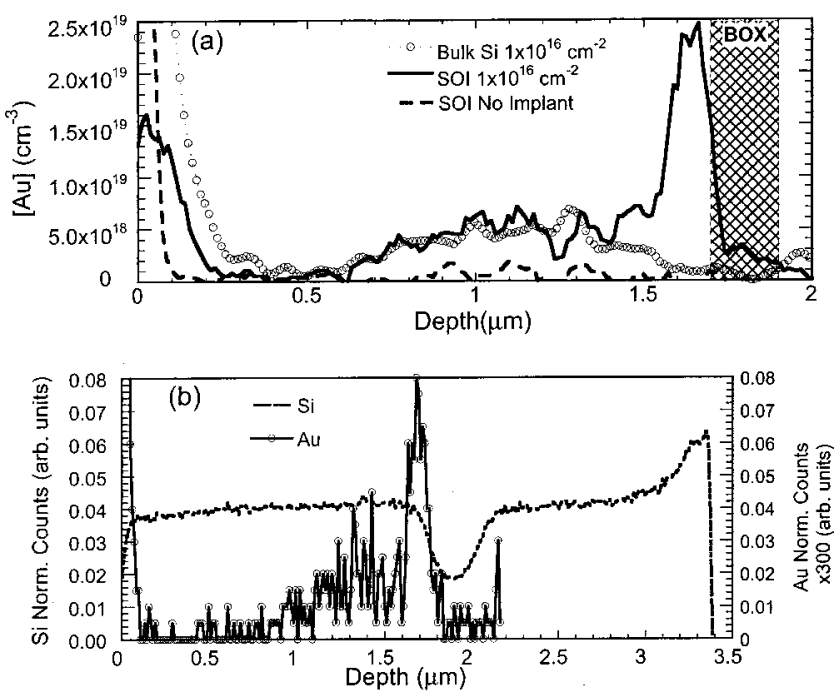

FIG. 1. (a) Experimentally observed Au profile after Au labeling for a SOI substrate (solid line) containing a high-energy implant (HEI) with $2 \mathrm{MeV} \mathrm{Si}$ at a dose of $1 \times 10^{16} \mathrm{~cm}^{-2}$. Also shown is the Au profile into a bulk Si wafer containing the identical HEI (open circles) and a SOI sample without the HEI (dashed line). The buried oxide layer (BOX) is indicated by the shaded area. (b) Overlaid signals of $\mathrm{Au}$ (open circles) and $\mathrm{Si}$ (dashed line) using the depth scales obtained via RBS. This overlay was used to determine that the rear edge of the extra Au peak in the SOI samples was at the front edge of the BOX layer

The Monte Carlo binary collision code TRIM98 (Ref. 16) was also used to determine the nature of the excess defects at the interface following the implantation. A $\mathrm{Si}(1.5 \mu \mathrm{m}) / \mathrm{SiO}_{2}(0.2 \mu \mathrm{m}) / \mathrm{Si}$ structure was used to simulate damage production due to a $2 \mathrm{MeV}{ }^{28} \mathrm{Si}$ implant at an incident angle of $7^{\circ}$. The atomic densities used were 6.98 $\times 10^{22}$ atoms $/ \mathrm{cm}^{3}$ for $\mathrm{SiO}_{2}$ and $4.98 \times 10^{22}$ atoms $/ \mathrm{cm}^{3}$ for $\mathrm{Si}$. The damage production was observed using a full damage cascade calculation. The displacement energy $\left(E_{d}\right)$ used for the $\mathrm{Si}$ substrate and the buried layer in this and all subsequent TRIM calculations was $15 \mathrm{eV}$. Additional TRIM simulations were carried out to determine the dependence of the excess defects at the front interface on the mass of atoms in the buried thin film. The implant parameters were identical to the previous simulation. These additional simulations were carried out using the $\mathrm{Si} / X / \mathrm{Si}$ heterostructure with the buried layer $X$ of thickness $0.2 \mu \mathrm{m}$ and density identical to $\mathrm{SiO}_{2}$ of $6.98 \times 10^{22}$ atoms $/ \mathrm{cm}^{3}$ but containing atoms of mass 12,28 , 31 , and $73 \mathrm{amu}$. The depth of the thin film was $1 \mu \mathrm{m}$ from the surface (as opposed to the earlier simulation where it was at a depth of $1.5 \mu \mathrm{m}$ ). Following the full cascade damage calculation, local recombination was used to determine the defect excess. In addition, the ballistic contribution to intermixing of the thin-film and substrate atoms was also followed.

\section{RESULTS AND DISCUSSION}

\section{A. Excess defects at the buried $\mathrm{Si} / \mathrm{SiO}_{2}$ interface: Experimental findings}

Figure 1(a) shows the typical Au profile obtained in a HEI sample with a $1 \times 10^{16} \mathrm{~cm}^{-2}$ dose Si implant in the SOI substrate. Also shown is the Au labeling into a SOI substrate 
without any HEI. Three distinct regions of Au can be identified in Fig. 1(a) for the HEI samples: the surface implanted Au peak in the region of $0-0.2 \mu \mathrm{m}$, the Au profile in the window of $0.5-1.5 \mu \mathrm{m}$, and the peak in the region between 1.6 and $1.8 \mu \mathrm{m}$. As compared to this, there is no Au trapped in the sample without any prior implant. The Au profile in the region of $0.5-1.5 \mu \mathrm{m}$ is known to arise due the $V^{\mathrm{ex}}$ defects. ${ }^{18}$ This region (referred to as the $V_{\mathrm{Si}}^{\mathrm{ex}}$ region) has been studied extensively in bulk float-zone $\mathrm{Si}^{14}$ We have recently shown ${ }^{13}$ that for the dose conditions used in this work, the $\mathrm{Au}$ concentration in the $V_{\mathrm{Si}}^{\mathrm{ex}}$ region is related to the $V^{\mathrm{ex}}$ concentration by a calibration factor $k=1.2$. To determine if the profile in the SOI sample was quantitatively similar to that obtained in the bulk FZ-Si substrates, the profiles from a 1 $\times 10^{16} \mathrm{~cm}^{-2}$ dose HEI in SOI and bulk FZ Si were compared. As shown in Fig. 1(a), after Au drive-in into the asimplanted samples, a similar profile was obtained for both substrates in the region of 0.5 to $\sim 1.5 \mu \mathrm{m}$. However, an essential difference between the Au profiles of the two substrates is the "extra" Au peak in the region between $\sim 1.6$ and $1.8 \mu \mathrm{m}$. To determine the precise position of this extra peak, the Au signal was overlaid with the Si substrate signal using the depth scales obtained via RBS..$^{20}$ As shown in Fig. 1(b), the rear edge of the Au peak corresponds to the front edge of the buried $\mathrm{SiO}_{2}$ thin film, as indicated by the dip in the $\mathrm{Si}$ signal. This proved that the $\mathrm{Au}$ peak in the region between $\sim 1.6$ and $1.8 \mu \mathrm{m}$ corresponded to $\mathrm{Au}$ at the front interface of the $\mathrm{Si} / \mathrm{SiO}_{2}$ layer.

To determine the nature of the defects that resulted in $\mathrm{Au}$ trapping in this interface region, extra $\mathrm{Si}$ atoms were added following the $1 \times 10^{16} \mathrm{~cm}^{-2}$ dose HEI implant. The extra atoms were then reacted with the existing defects at the interface by a $760{ }^{\circ} \mathrm{C}$ and $1020 \mathrm{~s}$ implant. If interstitial defects are present at the interface, the extra $\mathrm{Si}$ atoms will tend to cluster with them and under the chosen anneal conditions would ripen to create large interstitial clusters of \{311\}-type defects. ${ }^{21}$ These defects should show up as an increase in the concentration of trapped Au (Ref. 22) or be visible under TEM. On the other hand, if $V$-type defects are present at the interface, the extra $\mathrm{Si}$ atoms will recombine with some of the vacancies. This should lead to a decrease in the amount of Au trapped following Au labeling. Alternately, the extra atoms could rapidly recombine at the $\mathrm{Si} / \mathrm{SiO}_{2}$ interface, which is known to be a sink for interstitials, ${ }^{23}$ thereby leaving the defects and therefore the amount of trapped Au unchanged. Shown in Fig. 2(a) are the simulated TRIM implantation profiles for the low-energy $\mathrm{Si}$ atoms with respect to the experimentally measured position of the buried oxide layer. Also shown is the experimental Au profile for the SOI sample containing the $1 \times 10^{16} \mathrm{~cm}^{-2}$ Si HEI (and $760{ }^{\circ} \mathrm{C}$, $1020 \mathrm{~s}$ anneal). In Fig. 2(b) the result of implanting the extra $\mathrm{Si}$ atoms, as measured by Au labeling, is shown. Clearly, the amount of trapped Au has decreased after the second implant, indicating that these defects are $V$ type. The change in the $\mathrm{Au}$ concentration as a function of the implanted $\mathrm{Si}$ atoms is shown more clearly in Fig. 2(c). Here, the number of implanted $\mathrm{Si}$ atoms was estimated from the area under the curve between $1.3 \mu \mathrm{m}$ up to the front interface of the $\mathrm{Si} / \mathrm{SiO}_{2}$ region at $\sim 1.59 \mu \mathrm{m}$ [Fig. 2(a)]. The integrated doses were
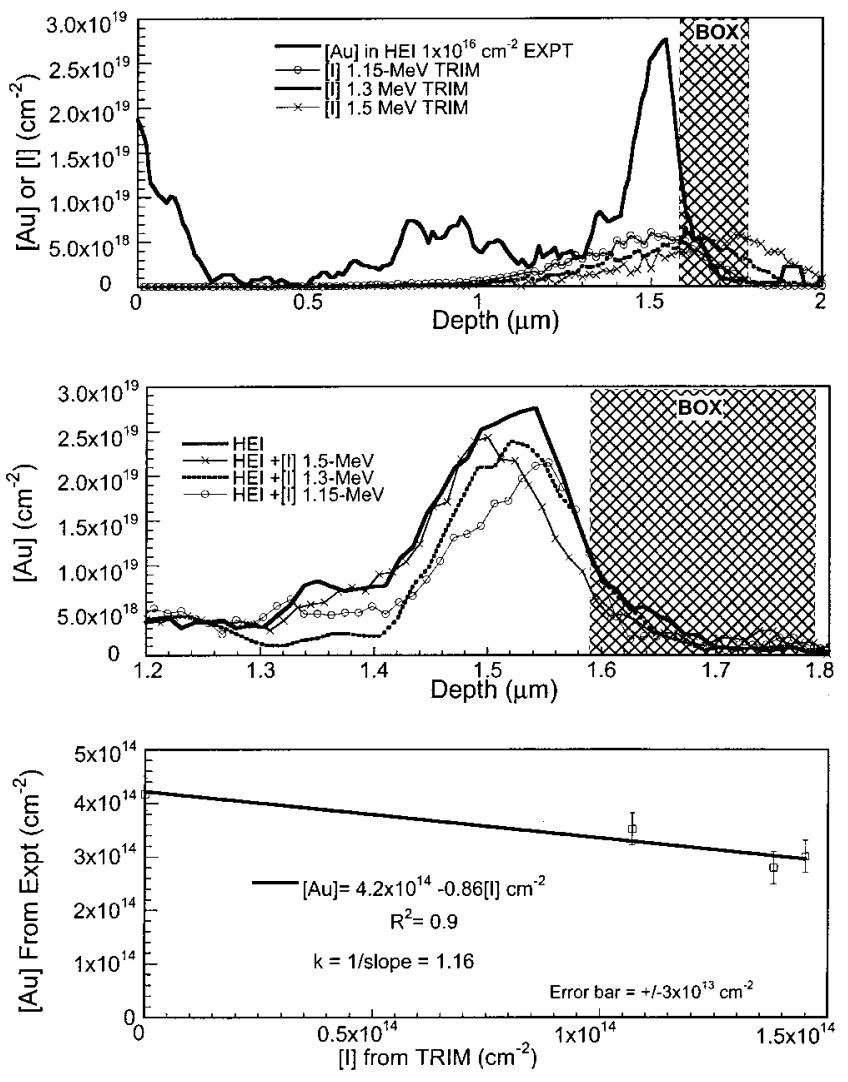

FIG. 2. (a) The experimentally observed $\mathrm{Au}$ profile for the $2 \mathrm{MeV}, 1$ $\times 10^{16} \mathrm{~cm}^{-2} \mathrm{Si}$ HEI (solid line) in comparison with the spatial distribution of the interstitials obtained from TRIM calculations following the lowenergy Si implants of 1.15-1.5 MeV. (b) Au profiles of the region near the buried interface following the interaction between the defects of the HEI and interstitials from the low-energy Si implants. (c) Integrated Au concentration after the various low-energy implants for the depth window of $1.3-1.59 \mu \mathrm{m}$ plotted against the number of Si interstitials obtained from the TRIM calculations of (a) for the same depth window. The slope of the linear decrease on the amount of $\mathrm{Au}(\sim 0.86)$ is identical to that obtained in the calibration experiment.

$1.45 \times 10^{14}, 1.38 \times 10^{14}$, and $1.07 \times 10^{14} \mathrm{~cm}^{-2}$ for the 1.15 , 1.3 , and $1.5 \mathrm{MeV}$ implants, respectively. The amount of trapped Au decreases linearly with the injected $\mathrm{Si}$ atoms. The slope of this variation, which gives the decrease in the number of $\mathrm{Au}$ atoms for every additional $\mathrm{Si}$ atom, is $\sim 0.86$ \pm 0.26 . The reciprocal of this ratio, which measures the number of interstitials needed to reduce the amount of trapped $\mathrm{Au}$ by 1 atom is $\sim 1.16 \pm 0.35$. This number is in agreement with our earlier observed value of $1.2 \pm 0.2$ for $V_{\mathrm{Si}}^{\mathrm{ex}}$ in $\mathrm{FZ} \mathrm{Si}$, which measured the number of vacancies required to trap 1 $\mathrm{Au}$ atom. Furthermore, the amount of $\mathrm{Si}$ atoms placed at the interface (the areal density varied from $1.07 \times 10^{14}$ to $\sim 1.45 \times 10^{14} \mathrm{~cm}^{-2}$ ) is large enough to form interstitial clusters $^{21}$ when implanted alone. However, transmission electron microscopy observations in cross section did not show any extended interstitial defects at the interface in the HEI samples containing the second Si implant. Therefore, these three results: the linear decrease in the interface $\mathrm{Au}$ with $\mathrm{Si}$ injection, the agreement in the $k$ value, and the absence of extended interstitial defects provides conclusive evidence that the existing defects at the interface (referred to as $\left.V_{\text {Int }}^{\mathrm{ex}}\right)$ following the HEI are $V$ type. 

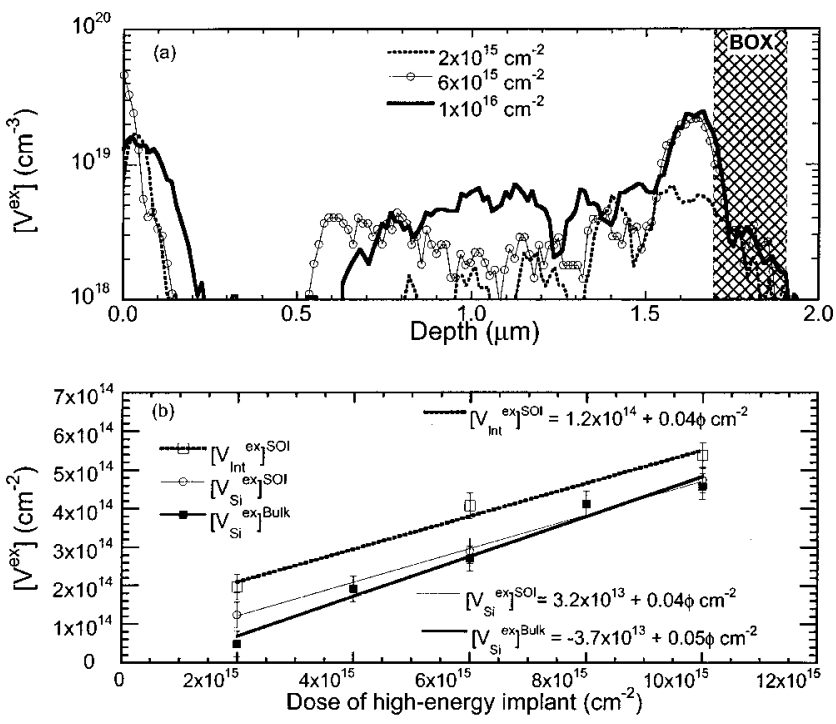

FIG. 3. (a) $V^{\text {ex }}$ profile for various doses of the $2 \mathrm{MeV}$ Si HEI obtained from Au labeling and calibration factor $k=1.2$. (b) Linear dose dependence was observed for the integrated (depth window of $0.5-1.5 \mu \mathrm{m}$ ) $\left[V_{\mathrm{Si}}^{\mathrm{ex}}\right]$ for the SOI (open circles) and bulk Si (solid squares). Also shown is the integrated $\left[V_{\mathrm{Int}}^{\mathrm{ex}}\right]$ (depth window of 1.5-1.8 $\mu \mathrm{m}$ ) for the interface region (open squares), which also shows a linear increase with HEI dose.

To further quantify the behavior of the $V_{\text {Int }}^{\text {ex }}$, a HEI dosedependent study was performed. Shown in Fig. 3(a) is the $V^{\text {ex }}$ profile for the SOI substrate as a function of HEI dose. Increasing dose increases $V_{\mathrm{Si}}^{\mathrm{ex}}$ as well as $V_{\mathrm{int}}^{\mathrm{ex}}$. Using calibration factor $k$ of 1.2 for the $V_{\mathrm{Si}}^{\mathrm{ex}}$ and $V_{\mathrm{int}}^{\mathrm{ex}}$ regions, the integrated $V^{\text {ex }}$ concentration for the two regions as a function of the implanted Si dose can be plotted, as in Fig. 3(b). The depth window used to determine the areal concentration was $0.5-$ $1.5 \mu \mathrm{m}$ for $V_{\mathrm{Si}}$ and 1.5-1.8 $\mu \mathrm{m}$ for $V_{\mathrm{Int}}$. Both regions show a linear increase with dose. Also shown in Fig. 3(b) is the $V_{\mathrm{Si}}^{\mathrm{ex}}$ region observed for the bulk FZ Si. Clearly, the slopes of the $V_{\mathrm{Si}}^{\mathrm{ex}}$ are within the error bars of these measurements $(\sim 15 \%)$. In addition, while the overall concentration of the $V_{\mathrm{Int}}^{\mathrm{ex}}$ is greater the slope is similar to the $V_{\mathrm{Si}}^{\mathrm{ex}}$ region. Thus, the $V_{\mathrm{Int}}^{\mathrm{ex}}$ region behaves similar to the $V_{\mathrm{Si}}^{\mathrm{ex}}$ region, suggesting that similar excess damage production mechanisms are operating for both cases.

\section{B. Excess defects at the buried $\mathrm{Si} / \mathrm{SiO}_{2}$ interface: Simulation}

Since binary collision codes have successfully predicted the existence of excess $V$-type defects in the $V_{\mathrm{Si}}^{\mathrm{ex}}$ region, ${ }^{24}$ we can use the Monte Carlo binary collision code TRIM to understand the effect of a buried thin film on the excess defect profile. Shown in Fig. 4(a) is the Frenkel pair profile produced following the $1 \times 10^{16} \mathrm{~cm}^{-2}$ dose HEI in the SOI substrate. Following local recombination, the excess defect concentration is shown in Fig. 4(b), where the ordinate is in terms of the vacancy excess. The experimentally observed $V^{\mathrm{ex}}$ is also shown. Besides the excess in the $V_{\mathrm{Si}}^{\mathrm{ex}}$ region from the surface to about $1.2 \mu \mathrm{m}$, there is also clearly a large $V$ peak at the front interface. Therefore, the experimentally observed $V_{\text {int }}^{\text {ex }}$ is qualitatively predicted by a simple binary collision calculation. The calculation of the excess as shown in
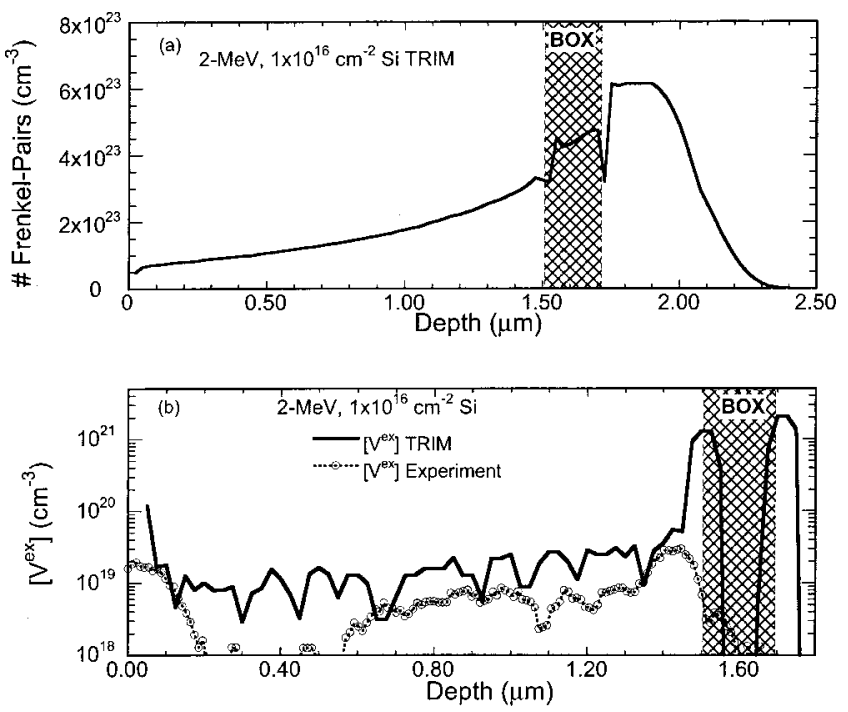

FIG. 4. (a) Frenkel pair profile obtained from the TRIM calculation for the $2 \mathrm{MeV}, 1 \times 10^{16} \mathrm{~cm}^{-2} \mathrm{Si}$ HEI in the SOI substrate containing a $0.2-\mu \mathrm{m}-$ thick BOX layer at a depth of $1.5 \mu \mathrm{m}$. (b) Excess vacancy defect profile following local recombination from the point defect distribution calculated from TRIM (solid line) compared to the experimentally observed $V^{\mathrm{ex}}$ profile for a $2 \mathrm{MeV}, 1 \times 10^{16} \mathrm{~cm}^{-2} \mathrm{Si}$ HEI. The depth scale of the experimental profile was stretched by a factor of $\times 1.15$ to align the buried interface position.

Fig. 4(b) was based on the total number of atoms, i.e., both $\mathrm{Si}$ and O. As Fig. 5 shows, a significant concentration of $\mathrm{O}$ (peak concentration is $\sim 4 \times 10^{18} \mathrm{~cm}^{-3}$ ) is intermixed across the $\mathrm{Si} / \mathrm{SiO}_{2}$ interface. The areal density of $\mathrm{O}$ in the $\mathrm{Si}$ side of the interface is $\sim 1.2 \times 10^{13} \mathrm{~cm}^{-2}$ for the $1 \times 10^{16} \mathrm{~cm}^{-2}$ dose. This indicates that intermixed atoms could contribute significantly to the total atom concentration at the interface and will play a role in determining the behavior of the defects at the interface. In fact, we have recently reported on the thermal behavior of excess vacancies and the possible effect of $\mathrm{O}$ on their behavior. ${ }^{25}$ Although the simulation predicts $V_{\text {int }}^{\text {ex }}$, a quantitative comparison between the experimentally observed $V_{\mathrm{int}}^{\mathrm{ex}}$ and the TRIM observations shows that the simulation predicts values that are almost $10 \times$ higher than

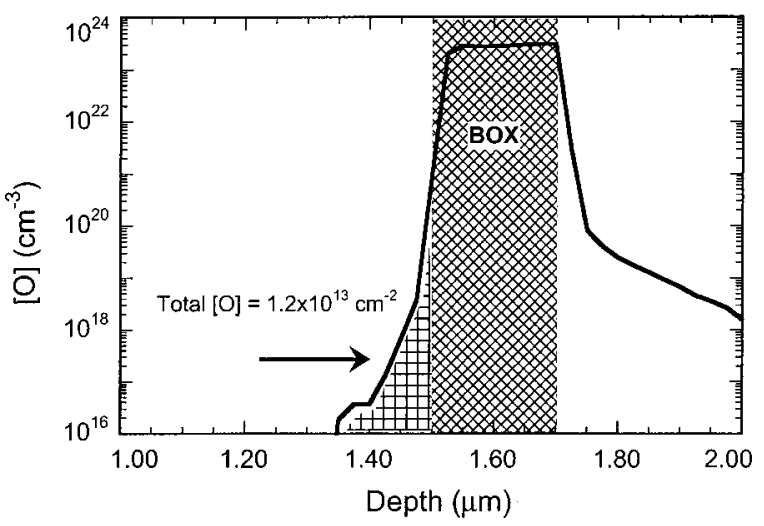

FIG. 5. Oxygen mixing profile following the TRIM calculation of a $2 \mathrm{MeV}$, $1 \times 10^{16} \mathrm{~cm}^{-2} \mathrm{Si}$ implant into the SOI substrate containing a $0.2-\mu \mathrm{m}$-thick BOX layer at a depth of $1.5 \mu \mathrm{m}$. The areal density of the intermixed oxygen was estimated for the dark shaded area, which corresponded to oxygen in the top Si layer. 


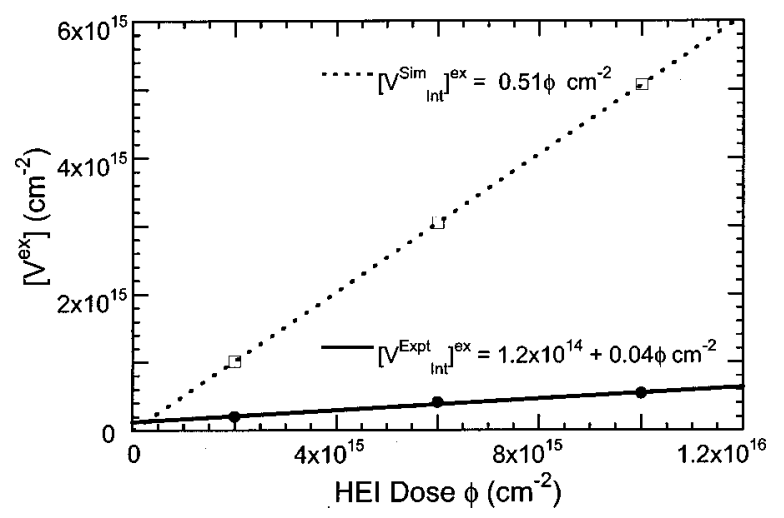

FIG. 6. Integral $V_{\mathrm{Int}}^{\mathrm{ex}}$ as a function of the HEI dose obtained from the TRIM simulations (open squares) compared to the experimentally observed values (solid circles).

that observed experimentally. Shown in Fig. 6 are the integral $V_{\text {int }}^{\text {ex }}$ from experiment and simulation. $V_{\text {int }}^{\text {ex }}$ is $\sim 10 \times$ higher for the TRIM calculation over experiment. It must be remembered that the TRIM simulation only involves local recombination of defects. In the experiment, the Au drive-in is carried out at $750^{\circ} \mathrm{C}$. Given the fact that point defects in $\mathrm{Si}$ are very mobile, the true $V^{\text {ex }}$ concentration must also take into account any dynamic effects following the recombination. A more sophisticated simulation taking into account the mobility and thermal stability of the various defect clusters and their interaction with impurities and interfaces must be used to give an accurate quantitative picture of the $V^{\text {ex }}$ generation. Nevertheless, the qualitative agreement obtained by using the simple binary collision code like TRIM allows a preliminary study of the effect of various implant and substrate parameters on excess defect production.

\section{Excess defects at buried $\mathrm{Si} / X / \mathrm{Si}$ structures: Simulation}

Given the qualitative success of the Monte Carlo calculation in verifying the nature of the excess defects at the interface, the study of various aspects of the excess defect production on thin-film properties can be attempted. As described earlier, hypothetical $0.2-\mu \mathrm{m}$-wide thin films containing atoms of mass $12,28,31$, and $73 \mathrm{amu}$ were placed at a depth of $1.0 \mu \mathrm{m}$ in these simulations. A $2 \mathrm{MeV}, 2$ $\times 10^{15} \mathrm{~cm}^{-2}$ dose Si implant was simulated and the resulting excess defect production was evaluated. Figure 7(a) shows the $V^{\mathrm{ex}}$ profiles in these TRIM calculations. The immediately apparent feature is the decrease in $V^{\text {ex }}$ at the frontside of the interface (between 0.98 and $1.0 \mu \mathrm{m}$ ) as a function of increasing mass. In fact, for the case of mass $73 \mathrm{amu}$, the excess defect becomes interstitial type $\left(I^{\mathrm{ex}}\right)$, indicating a crossover in the sign of the defect (i.e., $V^{\mathrm{ex}}$ to $I^{\mathrm{ex}}$ ) at some intermediate mass. Shown in Fig. 7(b) are the concentration profiles for impurity atoms intermixed into the Si side of the front interface and the $\mathrm{Si}$ atoms recoiled into the thin film. Here, the case for mass $=28 \mathrm{amu}$ is not plotted because the $X$ atoms could not be distinguished from the substrate $\mathrm{Si}$ atoms. In the estimation of the excess, the behavior of these intermixed impurity atoms, i.e., their substitutional vs. interstitial (1) character must be accounted for. While the substitutional im-
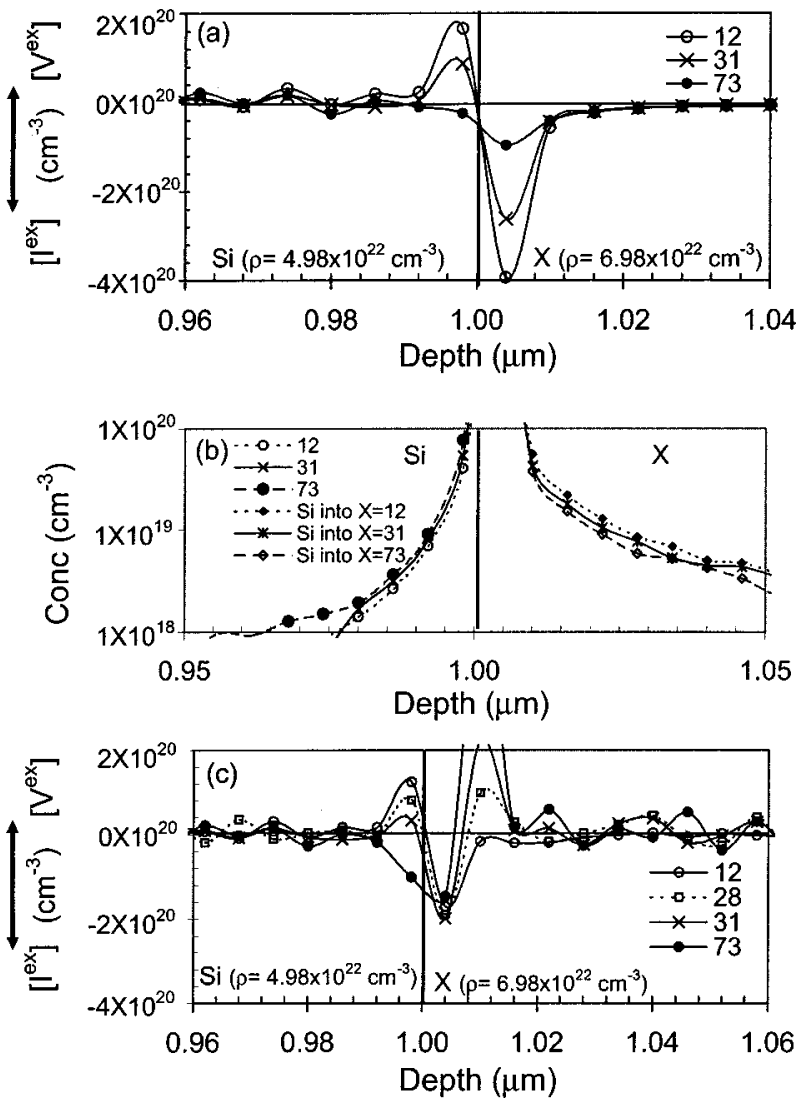

FIG. 7. (a) Simulated $V^{\text {ex }}$ profiles at the frontside of the $\mathrm{Si} / X / \mathrm{Si}$ structure as observed from TRIM simulations for various masses of $X$. The solid vertical line at $1 \mu \mathrm{m}$ denotes the front interface between $\mathrm{Si}$ and $X$. The profiles here were estimated by treating any intermixed atoms from $X$ to be interstitial type. All the simulations were for a $2 \mathrm{MeV}, 2 \times 10^{15} \mathrm{~cm}^{-2} \mathrm{Si}$ HEI into a $1-\mu \mathrm{m}$-thick top Si layer and $0.2-\mu \mathrm{m}$-thick $X$ layer. The $X$ layer had an atomic density of $6.98 \times 10^{22} \mathrm{~cm}^{-3}$. (b) Simulated concentration of the $X$ atoms intermixed into the $\mathrm{Si}$ side of the front interface and the $\mathrm{Si}$ atoms intermixed into the $X$ side. (c) Simulated $V^{\text {ex }}$ profiles at the front interface obtained by treating the intermixed $X$ atoms as substitutional impurities.

purities will annihilate vacancies, the I-type impurities will not. In the case of Fig. 7(a), the impurity was assumed to be $I$ type. If the impurities are considered substitutional, the result is a decrease in the $V^{\mathrm{ex}}$ and an increase in $I^{\mathrm{ex}}$. Figure 7 (c) shows the effect of substitutional impurities on the resulting excess defect profile. The case for $X$ of mass $=28 \mathrm{amu}$ is also included as now the $X$ atoms need not be distinguished from the substrate case. $V^{\text {ex }}$ has now decreased for the 12 and 31 amu cases, while $I^{\text {ex }}$ has increased for 73 amu. It should be emphasized here that the calculations were done for hypothetical layers having atomic density of 6.98 $\times 10^{22} \mathrm{~cm}^{-3}$. Therefore, the result for $X=28 \mathrm{amu}$, corresponding to $\mathrm{Si}$ atoms, shows an enhanced $V^{\mathrm{ex}}$ at the interface of the atomic density change. Similar calculations performed with $X=28$ but with the atomic density of Si did not show enhanced $V^{\mathrm{ex}}$.

Figure 8 plots the integrated $V^{\mathrm{ex}}$ at the front interface (the integral window is $\sim 0.9-1.0 \mu \mathrm{m}$ ) with and without the substitutional impurity atoms as a function of the mass of the thin-film atoms. Significantly, $V^{\mathrm{ex}}$ decreases linearly with increasing mass, with the position of the crossover from $V^{\mathrm{ex}}$ to $I^{\mathrm{ex}}$ occurring at approximately $61 \mathrm{amu}$ (for interstitial impu- 


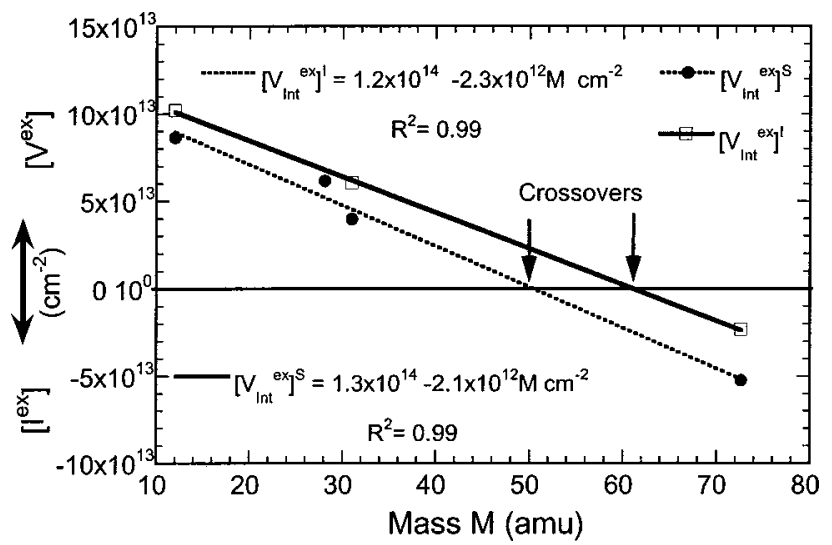

FIG. 8. Linear dependence of the $\left[V_{\mathrm{Int}}^{\mathrm{ex}}\right]$ on the mass of $X$ atoms as obtained from TRIM simulations. The position of the crossover, which indicates the position of change in the sign of the excess defect at the front interface, is also marked. The position of the crossover varies depending on the behavior of the intermixed $X$ atoms as interstitial or substitutional type. The crossover occurs at $\sim 61 \mathrm{amu}$ for interstitial-type $X$ atoms, while it occurs at $\sim 51 \mathrm{amu}$ for substitutional type. The calculations here are for the $2 \mathrm{MeV}, 2$ $\times 10^{15} \mathrm{~cm}^{-2} \mathrm{Si}$ implant into a $\operatorname{Si}(1.5 \mu \mathrm{m}) / X(0.2 \mu \mathrm{m}) / \mathrm{Si}$ heterostructure.

rities). For substitutional impurities, the crossover shifts to lower masses, and for this combination of Si implantation energy and depth of interface occurs at $\sim 51$ amu.

Table I lists the integral quantities of the Frenkel pair (FP) $(I$ and $V)$, the nuclear energy deposited, forward recoiled $\mathrm{Si}$ atoms, the impurity recoils, and the excess defects for the front interface. In general, there is a consistent variation in any quantity with increasing mass. For instance, the number of FPs in the Si substrate and the nuclear energy $\left(E_{d}^{\text {nuc }}\right)$ deposited in the thin film increases with increasing mass, while the $V^{\text {ex }}$ following the recombination of the FPs decreases. For the case when $X$ is 28 or 31, the comparable FP density for 28 as compared to 31 arises because of the increased efficiency of energy transfer between two atoms of identical mass (i.e., here the implanted ion has mass $28 \mathrm{amu}$ ) as compared to between the different masses. ${ }^{20}$ In addition, the number of impurity atoms intermixed into the frontside increases with mass, while the number of Si recoils in the thin film decreases with increasing mass for the depth window of $1.01-1.1 \mu \mathrm{m}$.

The net excess defect density following ion implantation through interfaces can be understood by considering the flux of atoms to various regions near the interfaces. For an elemental volume $d V$ at a position $P$ [Fig. 9(a)], the net rate of (a)
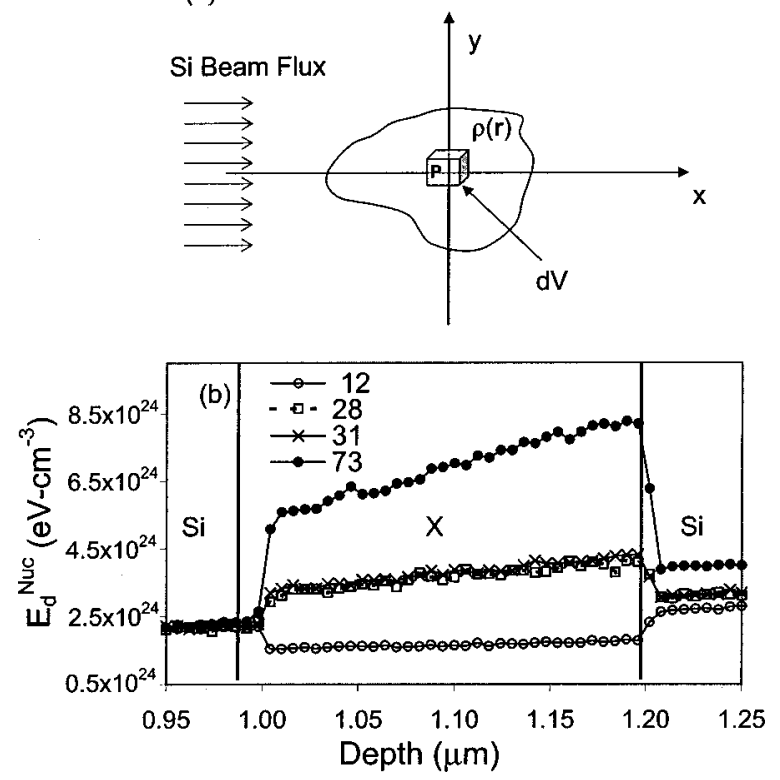

FIG. 9. (a) Net excess defect concentration following implantation in regions where the recoil production is changed over the bulk values can be estimated by the net flux of atoms into elemental volume $d V$ from the surrounding regions. The function $\rho(\hat{r})$ determines the probability that an atom from a neighboring region will be knocked into $d V$. Thus, integration of $\rho(r)$ over the volume neighboring $d V$ minus the number of atoms coming out from $d V$ determines the net flux from which the net excess is determined. (b) TRIM calculation of the total energy deposited to nuclear stopping $\left(E_{d}^{\text {Nuc }}\right)$ for the various $X$ layers used. Change in $E_{d}^{\text {Nuc }}$ in going from the bulk $\mathrm{Si}$ to the $X$ layer provides one situation by which the recoil production in the $X$ layer is different from bulk Si.

change in the number of atoms it contains is determined mainly by two factors; (i) the recoils from neighboring regions that stop in $d V$, and (ii) the atoms knocked out of $d V$ by energetic collisions. We define a function $\rho(\dot{r})$, which is the rate per unit volume at which atoms from the neighboring regions are scattered by the ion-beam flux (including recoils, etc.) and come to rest in the volume element $d V$. The net flux to point $P$ (into $d V$ ) is the integral of $\rho(\dot{r})$ over the surrounding regions, where $\rho(\dot{r})$ is nonzero, minus the rate at which atoms are kicked out of $d V$. In the homogeneous bulk, the net change in the number of atoms in $d V$ is relatively small (the excess vacancies obtained experimentally are very small compared to the total point defect populations). However, if there is an inhomogeneity; i.e., a neighboring region where the recoil production rate is different

TABLE I. Results of the TRIM simulation for the $2 \mathrm{MeV}, 2 \times 10^{15} \mathrm{~cm}^{-2} \mathrm{Si}$ implant into $\mathrm{Si}(1.0 \mu \mathrm{m}) / X(0.2 \mu \mathrm{m}) / \mathrm{Si}$ heterostructure for the front $\mathrm{Si} / X$ interface. The excess defects are calculated in the $\mathrm{Si}$ side of the front interface in the depth window of $0.9-1.0 \mu \mathrm{m}$. The density of $X$ for all the masses was $\sim 6.98 \times 10^{22}$ atoms $/ \mathrm{cm}^{3}$

\begin{tabular}{|c|c|c|c|c|c|c|}
\hline \multirow{2}{*}{$\begin{array}{l}X \text { atom Mass } \\
\quad(\mathrm{amu})\end{array}$} & \multirow{2}{*}{$\begin{array}{l}\text { No. of FPs } \\
\left(\mathrm{cm}^{-2}\right) \\
<1.0 \mu \mathrm{m}\end{array}$} & \multirow{2}{*}{$\begin{array}{c}E_{d}^{\mathrm{Nuc}} \\
(\mathrm{eV} / \mathrm{ion}) \\
<1.0 \mu \mathrm{m}\end{array}$} & \multirow{2}{*}{$\begin{array}{c}\text { Si recoils } \\
\left(\mathrm{cm}^{-2}\right) \\
>1.0 \mu \mathrm{m}\end{array}$} & \multirow{2}{*}{$\begin{array}{l}X \text { recoils } \\
\left(\mathrm{cm}^{-2}\right) \\
<1.0 \mu \mathrm{m}\end{array}$} & \multicolumn{2}{|c|}{$\begin{array}{l}\text { Excess defects }\left(\mathrm{cm}^{-2}\right) \\
+v e \text { for } V^{\mathrm{ex}}-v e \text { for } l^{\mathrm{ex}}\end{array}$} \\
\hline & & & & & Substitutional & Interstitial \\
\hline 12 & $3.1 \times 10^{17}$ & $6.3 \times 10^{9}$ & $8.3 \times 10^{13}$ & $1.6 \times 10^{13}$ & $8.6 \times 10^{13}$ & $1 \times 10^{14}$ \\
\hline 28 & $3.3 \times 10^{17}$ & $1.2 \times 10^{10}$ & & & $6.2 \times 10^{13}$ & \\
\hline 30 & $3.3 \times 10^{17}$ & $1.3 \times 10^{10}$ & $6.7 \times 10^{13}$ & $2.1 \times 10^{13}$ & $4 \times 10^{13}$ & $6 \times 10^{13}$ \\
\hline 73 & $3.6 \times 10^{17}$ & $2.4 \times 10^{10}$ & $5.7 \times 10^{13}$ & $2.9 \times 10^{13}$ & $-5.3 \times 10^{13}$ & $-2.3 \times 10^{13}$ \\
\hline
\end{tabular}


from that in bulk $\mathrm{Si}$, then another function $\rho^{*}(\dot{r})$ must be used in this region and the rate of accumulation of atoms in $d V$ will be different from the bulk value. For instance, if $P$ is close to a free surface, then $\rho^{*}(\dot{r})$ is zero beyond the surface, since the vacuum contributes nothing to the accumulation of atoms in $d V$. The rate of loss from $d V$ is not affected by the presence of the surface, and therefore the approximate balance between the incoming and outgoing atoms in $d V$ will be lost. In most cases where $P$ is near a surface, net vacancies can be expected to accumulate in $d V$.

An effect that can cause a change in the recoil production rate near interfaces between different materials is the nuclear energy deposited into the material because of a different mass, ${ }^{4}$ atomic density, etc., as compared to Si. From the simulations carried out here, the $E_{d}^{\mathrm{Nuc}}$ (in $\mathrm{eV} \mathrm{cm}^{-3}$ ) increases with increasing mass [Fig. 9(b)], as expected. ${ }^{4}$ In addition, the $E_{d}^{\text {Nuc }}$ changes rapidly in going across the interface. This leads to a change in recoil production across the interface and from our flux model provides a condition for an excess defect concentration that is enhanced over the bulk value. Further, the increasing $E_{d}^{\text {Nuc }}$ will increase the cascade size (and the density of cascades) causing a "spillover" of mass and energy across the interface. This spillover is clearly manifested in the increase in the number of recoiled impurity atoms from the interface with increasing mass [Fig. 7(b)], and therefore changes the net flux in $d V$ compared to the situation in bulk Si. These preliminary qualitative findings from the TRIM calculations emphasize that the mass of the interface atoms play an important role in the net excess defect population at the interface. Importantly, these simulations show that the defect type and/or defect density at the front interface can be controlled. While this model can be used to understand the presence of the $V^{\mathrm{ex}}$ peak at various interfaces, for instance, at the back $\mathrm{SiO}_{2} / \mathrm{Si}$ interface [Fig. 4(b)], it does leaves out secondary effects, such as the reduction in the energetic particle flux with distance.

\section{CONCLUSION}

The experiments reported here have clearly identified the nature of defects produced at a front interface of a buried thin film during irradiation of a heterostructure. Excess defects were created by a high-energy implant of $2 \mathrm{MeV}$ Si into a SOI substrate containing $\mathrm{Si}(1.8 \mu \mathrm{m}) / \mathrm{SiO}_{2}(0.2 \mu \mathrm{m}) / \mathrm{Si}$. The Au labeling technique was then used to profile the excess defects. Besides Au trapping in the well-characterized excess vacancy-type defect region in the top Si region $\left(V_{\mathrm{Si}}^{\mathrm{ex}}\right)$, additional $\mathrm{Au}$ trapping was observed at the frontside of the buried $\mathrm{Si} / \mathrm{SiO}_{2}$ interface. The nature of defects resulting in this trapping was investigated by additional low-energy $\mathrm{Si}$ implants. Following the low-energy Si implant and annealing at $760{ }^{\circ} \mathrm{C}$ for $1020 \mathrm{~s}$, Au labeling showed a linear decrease in the amount of trapped $\mathrm{Au}$ with $\mathrm{Si}$ interstitial dose. The ratio of the number of $\mathrm{Si}$ atoms injected to the reduction in number of Au atoms trapped, $k^{\text {lnt }}$, was $\sim 1.16 \pm 0.35$. TEM measurements did not show the presence of any extended interstitial-type defects. Therefore, the decrease in trapped $\mathrm{Au}$ with increasing number of low-energy $\mathrm{Si}$ atoms, the close correspondence of the $k^{\text {lnt }}$ to $k(1.2 \pm 0.2)$, and the lack of evidence of extended interstitial defects, clearly proved that the defects at the frontside of the buried interface were vacancy type. The concentration of the $V_{\text {lnt }}^{\mathrm{ex}}$ was found to increase linearly with increasing HEI dose with a slope similar to that of the $V_{\mathrm{Si}}^{\mathrm{ex}}$ suggesting that a similar damage production mechanism is involved at the interface.

Monte Carlo simulations of $2 \mathrm{MeV} \mathrm{Si}$ implantation into a $\mathrm{Si}(1.5) / \mathrm{SiO}_{2}(0.2 \mu \mathrm{m}) / \mathrm{Si}$ heterostructure confirmed the existence of excess vacancy-type defects at the frontside of the buried interface. Further simulations were performed on structures of type $\operatorname{Si}(1.0 \mu \mathrm{m}) / X(0.2 \mu \mathrm{m}) / \mathrm{Si}$ using $2 \mathrm{MeV}$ $\mathrm{Si}$, and varying the mass of $X$ from that of $12-73 \mathrm{amu}$. The mass of $X$ was found to be a very important parameter in the concentration of the excess defects at the front interface. A change in sign of the excess defect from $V$ to $I$ type at the front interface occurred for a mass of $\sim 61$ amu or greater, when the defects were treated as interstitial type. This transition shifted to lower mass ( $\sim 51$ amu) when the impurity atoms from the buried layer were treated as substitutionaltype defects.

The experimental results and Monte Carlo simulations suggest that it may be possible to control the sign of the defect at buried interfaces. This may be an important effect considering the fact that point defects and their clusters at the interface can be used to tailor the strain of the overlayer. For instance, consider the presence of vacancy clusters near the front interface of a $\mathrm{Si} / X / \mathrm{Si}$ heterostructure, wherein the top $\mathrm{Si}$ layer is sufficiently thin. In this case, a thin overlayer of $\mathrm{Si}$ can be subject to slightly larger compressive stresses, simply because of the additional available volume provided by the clusters. The sign of the applied stress can be reversed if instead of vacancies, an excess of interstitials existed at the interface. In other words, it is possible to envision tailoring the overlayer to accommodate an appropriate stress simply by choosing the right combination of the buried layer mass and implant parameter.

\section{ACKNOWLEDGMENTS}

The authors are indebted to Cliff King and George Celler for providing the SOI wafers. Many enlightening moments have been spent with members in the "party room" at Bell Laboratories and they will be missed. One of the authors ( $R$. K.) also thanks Karl-Heinz Heinig for useful discussions. Research performed at Oak Ridge National Laboratory was sponsored in part by Oak Ridge Associated Universities under Contract No. DE-AC05-76OR00033 and by the U.S. Department of Energy, Office of Science, Laboratory Technology Research Division and the Division of Materials Sciences under Contract No. DE-AC05-00OR22725 with UT-Battelle, LLC.

${ }^{1}$ R. F. Wolffenbuttel, J. Micromech. Microeng. 6, 138 (1996); K. Vanhollebeke, I. Moerman, P. Van Daele, and P. Demeester, Prog. Cryst. Growth Charact. Mater. 41, 1 (2000).

${ }^{2}$ See review by U. Gösele and Q.-Y. Tong, Annu. Rev. Mater. Sci. 28, 215 (1998).

${ }^{3}$ J. W. Mayer and S. S. Lau, in Surface Modification and Alloying (Plenum, New York, 1983); L. C. Feldman and J. W. Mayer, in Fundamentals of Surface and Thin-Film Analysis, North-Holland, NY (1986).

${ }^{4}$ M. Nastasi and J. W. Mayer, Mater. Sci. Eng., R. R12, 1 (1994). 
${ }^{5}$ A. Uedono, T. Kitano, M. Watanabe, T. Moriya, T. Kawano, S. Tanogawa, R. Suzuki, T. Ohdaira, and T. Mikado, Jpn. J. Appl. Phys., Part 1 35, 2000 (1996).

${ }^{6}$ R. A. Brown and J. S. Williams, J. Appl. Phys. 81, 7681 (1997).

${ }^{7}$ M. Tamura, T. Ando, and K. Ohyu, Nucl. Instrum. Methods Phys. Res. B 59/60, 572 (1991).

${ }^{8}$ M. B. Huang and I. V. Mitchell, J. Electron. Mater. 28, 385 (1999).

${ }^{9}$ J. Y. Cheng, D. J. Eaglesham, D. C. Jacobson, P. A. Stolk, J. L. Benton, and J. M. Poate, J. Appl. Phys. 80, 2105 (1996).

${ }^{10}$ D. J. Eaglesham, P. A. Stolk, H.-J. Gossmann, and J. M. Poate, Appl. Phys. Lett. 65, 2305 (1994)

${ }^{11}$ H.-H. Vuong, H.-J. Gossmann, L. Pelaz, G. K. Celler, D. C. Jacobson, D. Barr, J. Hergenrother, D. Monroe, V. C. Venezia, C. S. Rafferty, S. J. Hillenius, J. McKinley, F. A. Stevie, and C. Granger, Appl. Phys. Lett. 75, 1083 (1999).

${ }^{12}$ O. W. Holland, L. Xie, B. Nielsen, and D. S. Zhou, J. Electron. Mater. 25, 99 (1996); S. L. Ellingboe and M. C. Ridgway, Nucl. Instrum. Methods Phys. Res. B 127/128, 90 (1997); C. Szeles, B. Nielsen, P. Asoka-Kumar, K. G. Lynn, M. Anderle, T. P. Ma, and G. W. Rubloff, J. Appl. Phys. 76, 3403 (1994).

${ }^{13}$ R. Kalyanaraman, T. E. Haynes, V. C. Venezia, D. C. Jacobson, H.-J. Gossmann, and C. S. Rafferty, Appl. Phys. Lett. 76, 3379 (2000).

${ }^{14}$ R. Kalyanaraman, T. E. Haynes, D. C. Jacobson, H.-J. Gossmann, and C. S. Rafferty, Mater. Res. Soc. Symp. Proc. 610, B9.4.1 (2000).
${ }^{15}$ J. P. Biersack and L. G. Haggmark, Nucl. Instrum. Methods 174, 257 (1980).

${ }^{16}$ J. F. Ziegler, J. P. Biersack, and U. Littmark, The Stopping and Ranges of Ions in Solids (Pergamon, New York, 1985).

${ }^{17}$ R. Kalyanaraman, T. E. Haynes, V. C. Venezia, D. C. Jacobson, H.-J. Gossmann, and C. S. Rafferty, Mater. Res. Soc. Symp. Proc. 610, B9.2.1 (2000).

${ }^{18}$ V. C. Venezia, T. E. Haynes, A. Agarwal, L. Pelaz, H.-J. Gossmann, D. C. Jacobson, and D. J. Eaglesham, Appl. Phys. Lett. 74, 1299 (1999).

${ }^{19}$ The saturation time for the $\mathrm{Au}-V^{\mathrm{ex}}$ trapping is found to depend upon the total $V^{\text {ex }}$ concentration; R. Kalyanaraman, T. E. Haynes, O. W. Holland, and G. H. Gilmer, J. Appl. Phys. (submitted).

${ }^{20}$ See, for instance, W.-K. Chu, J. W. Mayer, and M.-A. Nicolet, Backscattering Spectrometry (Academic, Orlando, FL, 1978).

${ }^{21}$ D. J. Eaglesham, P. A. Stolk, H.-J. Gossmann, T. E. Haynes, and J. M. Poate, Nucl. Instrum. Methods Phys. Res. B 106, 191 (1995).

${ }^{22}$ J. Wong-Leung, E. Nygren, and J. S. Williams, Appl. Phys. Lett. 67, 416 (1995).

${ }^{23}$ D. Tsoukalas, C. Tsamis, and J. Stomenos, Appl. Phys. Lett. 63, 3167 (1983).

${ }^{24}$ A. M. Mazzone, Phys. Status Solidi A 95, 149 (1986); K. B. Winterbon, Radiat. Eff. 46, 181 (1980).

${ }^{25}$ R. Kalyanaraman, T. E. Haynes, O. W. Holland, H.-J. L. Gossmann, C. S. Rafferty, and G. H. Gilmer, Appl. Phys. Lett. 79, 1983 (2001). 
